\title{
Towards the Understanding of Lubrication Mechanisms in Total Knee Replacements - Part l: Experimental Investigations
}

NEČAS, D.; VRBKA, M.; MARIAN, M.; ROTHAMMER, B.; TREMMEL, S.; WARTZACK, S.; GALANDÁKOVÁ, A.; GALLO, J.; WIMMER, M.; KŘUPKA, I.; HARTL, M.

Tribology International

Volume 156, April 2021, Pages 1-13

ISSN: 0301-679X

DOI: https://doi.org/10.1016/j.triboint.2021.106874

Accepted manuscript 


\section{Towards the Understanding of Lubrication Mechanisms in Total Knee Replacements} - Part I: Experimental Investigations

$$
\text { David Nečas }{ }^{1, *} \text {, Martin Vrbka }{ }^{1} \text {, Max Marian², Benedict Rothammer }{ }^{2} \text {, Stephan Tremmel }{ }^{3} \text {, Sandro }
$$
Wartzack $^{2}$, Adéla Galandáková ${ }^{4}$, Jiř́ Gallo ${ }^{5}$, Markus A. Wimmer ${ }^{6}$, Ivan Křupka ${ }^{1}$, Martin Hartl ${ }^{1}$

${ }^{1}$ Department of Tribology, Faculty of Mechanical Engineering, Brno University of Technology, Technická 2896/2, 61669 Brno, Czech Republic

${ }_{2}^{2}$ Engineering Design, Friedrich-Alexander-Universität Erlangen-Nürnberg (FAU), Martensstr. 9, 91058 Erlangen, Germany

${ }^{3}$ Engineering Design and CAD, University of Bayreuth, Universitätsstr. 30, 95448 Bayreuth, Germany

${ }^{4}$ Department of Medical Chemistry and Biochemistry, Faculty of Medicine and Dentistry, Palacky University Olomouc, Hněvotínská 3, 77515 Olomouc, Czech Republic

${ }^{5}$ Department of Orthopaedics, Faculty of Medicine and Dentistry, Palacky University Olomouc, University Hospital Olomouc, I. P. Pavlova 6, 77520 Olomouc, Czech Republic

${ }^{6}$ Department of Orthopedic Surgery, Rush University Medical Center, 1611 W. Harrison St., 60612 Chicago, Illinois, USA

"Corresponding author,Tel.: +420 541143 239, E-mail address: David.Necas@vut.cz

\section{Abstract}

This contribution is aimed at the detailed understanding of lubrication mechanisms within total knee replacement. While Part I is focused on the experimental investigation, Part II deals with the development of a predictive numerical model. Here, a knee simulator was used for direct optical observation of the contacts between a metal femoral and a transparent polymer components. Transient dynamic conditions were applied. Mimicked synovial fluids with fluorescently labelled constituents were used as the test lubricants. The results showed that $\gamma$-globulin forms thin boundary lubricating film, being reinforced by the interaction of phospholipids and hyaluronic acid. Further development of 
lubricating film is attributed to albumin layering. Based on the results, a novel lubrication model of the knee implant is proposed.

\section{Keywords}

Total knee replacement, Knee simulator, Fluorescent microscopy, Lubrication, Experiment

\section{Introduction}

Surgery known as total knee arthroplasty (TKA) is bringing relief from pain and improving the knee function for up to 25 years after the surgery for the majority of patients [1],[2]. The numbers of TKAs done world-wide continue to grow with a current rough estimation of about two million TKA surgeries performed annually [3],[3]. Aseptic loosening in conjunction with periprosthetic osteolysis have been reported to be a leading long-term cause of TKA failure to date [5]. Osteolysis has been causally linked to wear of polyethylene surfaces. This pathogenic concept has been supported by isolation of a huge amounts of polyethylene particles in the periprosthetic tissues, histopathological examination of retrieved periprosthetic tissues, and a wide range of experimental studies [6]. Since the introduction of highly cross-linked polyethylene (HXLPE) in TKA, the reasons for revision of TKA have gradually changed in favor of alternative causes of TKA failure [7],[8]. This change is a consequence of the increasing use of HXLPE that was initially reserved for applications in total hip arthroplasty (THA) [9]. While there is not information yet available, based on registry data roughly $80 \%$ of TKAs survive 25 years [10]. In order to increase the life span, more tribological fine tuning might be helpful Joint surface wear has been studied in both THA [11] and in TKA [12]. Despite the fact that the basic typology of material damage is very similar [13],[14],[15],[16], there are obvious differences regarding wear rates [17]. Generally speaking, the wear performance of TKA depends on in vivo loading, design factors of the implant, and surgical and patient-specific factors. For example, polyethylene damage in a TKA may depend on gait characteristics [18] or the locking mechanism of the polyethylene insert in the metal tray [19]. Despite all the technological developments, the material characteristics of the implant play an important role [20]. 

enormous increase in the amount of TKA surgeries in the USA [21] and most likely worldwide. More and more, TKA is implanted in ever younger patients, which requires longer survival times of the implant. Although, HXLPE liners exhibit lower wear rate in comparison to non-XLPE [22], this may not always translate into fewer particles in vivo [23]. Also, a detectable surface damage of retrieved HXLPE liners from aseptically failed TKAs has been observed [13],[24]. Finally, there is an uncertainty related to a reduced inflammatory and osteolytic potential of HXLPE particles [25],[26] despite that some studies report their decreased specific biological activity [27],[28]. Clearly, there is a higher proportion of smaller particles produced by HXLPE compared to non-XLPE [29]. Taken together, there is still room for further tribological improvements of TKA. In this context, it is vital to understand the individual biotribological situation and wear behavior in a particular TKA over time, and dependent on everyday activities. This includes the study of the formation and retention of lubricant films. Ideally, tribological testing should conform to ISO 14243 [30], [31], which is an established standard for wear rate assessment of knee replacements [32]. The main motivation of using standardized conditions is in ability of comparison of the findings and data across various simulators, approaches and methodologies. Apparently, ISO is not able to cover all the clinical performance considering various activities or the effects such as sudden impacts. However, it should be noted that when revealing the fundamentals, the standards provide a suitable base which is frequently followed by researchers.

Assuming wear is considerably influenced by lubrication performance, and the efficiency of lubrication thus remarkably influences the implant lifetime [33], it must be emphasized that the lubrications mechanisms within TKA have not yet been sufficiently clarified. While few studies reported in literature deal with numerical simulation, see Part II [34], even less focus was on experimental investigation. A pilot study employed a technique based on resistivity measurement when detecting thickness of the lubricant layer in the contact between a metal ball and a conductive silicone rubber layer representing the tibial insert [35]. The contact was lubricated by silicone oils while the authors mostly focused on the influence of contact geometry. It was concluded that an ellipse-like contact with transversely elongated ellipse supported thicker films compared to a longitudinal ellipse or circle shaped contact. The importance of synovial fluid lubrication was later highlighted by Scholes et al. [36],[37] 
who studied the influence of kinematics and loading conditions on biotribological performance of hip implants and a prototype of polyurethane (PU) unicondylar knee replacement [36]. A prototype of PU knee implant was further investigated in terms of wear and lubrication in the subsequent paper [37]. Among others, the authors pointed out that the adsorbed proteins form solid-like films protecting the surfaces against extensive wear. The necessity of proper selection of the model lubricant was discussed as well. This statement is supported by later investigation provided by Bortel et al. [38]. The authors pointed out that often-employed calf serum may hardly mimic behavior of synovial fluid. The authors suggested model fluids containing proteins, hyaluronic acid (HA), phospholipids (PLs), and salts. It was concluded that proper composition of model fluid may provide clinically realistic friction and wear data when testing the prosthesis. Further investigation aimed at the detailed assessment of the influence albumin protein, which is dominant in both calf serum and synovial fluid, on wear of ultra-high molecular weight polyethylene (UHMWPE) [39]. It is suggested that conformational changes of albumin due to binding bilirubin contained in the fluid may lead to the formation of the bridges between UHMWPE and metal counterfaces, which eventually leads to elevated wear rate. The authors further found that these conformational changes may be prevent by the interaction of albumin with fatty acid. Nevertheless, it is assumed that albumin behavior has a substantial impact on wear processes within metal-PE implants. PE wear is further influenced by variations in constituent fractions [40], antimicrobial agents, polypeptides, or dilutive media [41]. The effect of dilutive media on wear of XLPE was studied by Guenther et al. [42]. The authors concluded that phosphate buffered saline should be a preferable media when differentiating the materials behavior maintaining the clinical relevance. Assuming that composition of synovial fluids of individuals substantially varies [43], laboratory investigation unnecessarily suffers from some uncertainty.

Lubrication mechanisms of knee implants were later investigated in more detail by Flannery et al. [44],[45]. In particular, the combined role of protein adsorption was explored while the protective function of adsorbed layer was confirmed despite elevated friction level. These studies further highlighted the fundamental role of the lubricant nature when experimentally testing the knee replacements. Following the suggestions about the importance of lubrication, a knee simulator was developed for the ability of direct in situ observation of the contact between real-shaped knee implant 
components [46]. A pilot study introducing the general principle and methodology was recently followed by the study aimed at the behavior of the dominant proteins in model synovial fluid [47]. Using the simulator and fluorescent imaging, it is possible to observe the formation of the film containing key blood plasm proteins, HA and phospholipids PLs in appropriate concentrations. This approach has previously been employed successfully when the lubrication mechanisms within THA joints were studied [48],[49]. The results for swing phase showed considerable differences in the contact appearance. With respect to the synovial film formation, a pronounced interplay between the different molecules was found. Thereby, the lubricant layer thickness stabilized within roughly 30 to $50 \mathrm{~s}$ for most of the lubricants with clear differences for specific test fluids. Protein agglomerations were present over the entire contact area and could be clearly detected. However, the study was mainly limited by the assumption of simplified loading and kinematic conditions that did not completely correspond to actual gait cycles, possibly affecting lubricant film formation process. to be further investigated. As presented above, most of the experimental studies used simplified geometries and/or inappropriate lubricant and/or experimental conditions. Thus, the main motivation of the present contribution was to experimentally assess the formation of the lubricating film, focusing on the specific synovial fluid constituents with respect to (i) implant geometry, (ii) actual fluid behavior, and (iii) loading and kinematic conditions during gait. Moreover, both the lateral and medial compartments were analyzed. In order to further investigate the mechanistic interactions of the synovial fluid constituents during lubrication, a sophisticated numerical model was employed that is presented in the Part II of the study [34].

\section{Materials and methods}

\subsection{Knee joint apparatus, measurement method}

The experiments were realized using a simulator, which enables the investigation of both THAs and TKAs with the use of the specific measurement modules. The machine was presented in more detail in a previous paper [47]. The tibial plateau was fixed in a frame performing motion in anterior/posterior (AP) direction and theoretically enabling application of internal/external (IE) rotation. The femoral 

the microscope to be set to the specific position. Otherwise, such a complex observation could not be done due to large contact area migration along AP direction. The CAD model of the test device, the knee module and real appearance of illuminated test specimens are shown in Fig. 1.

146

$\mathbf{A}$

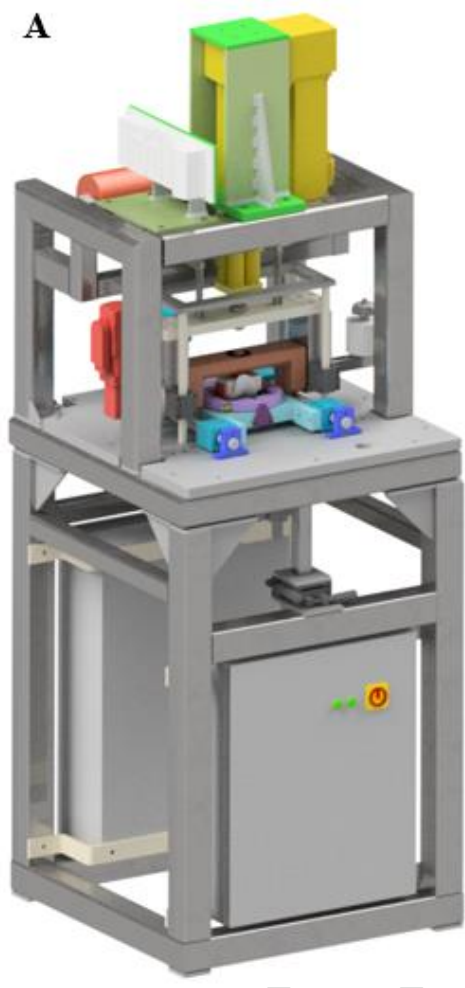

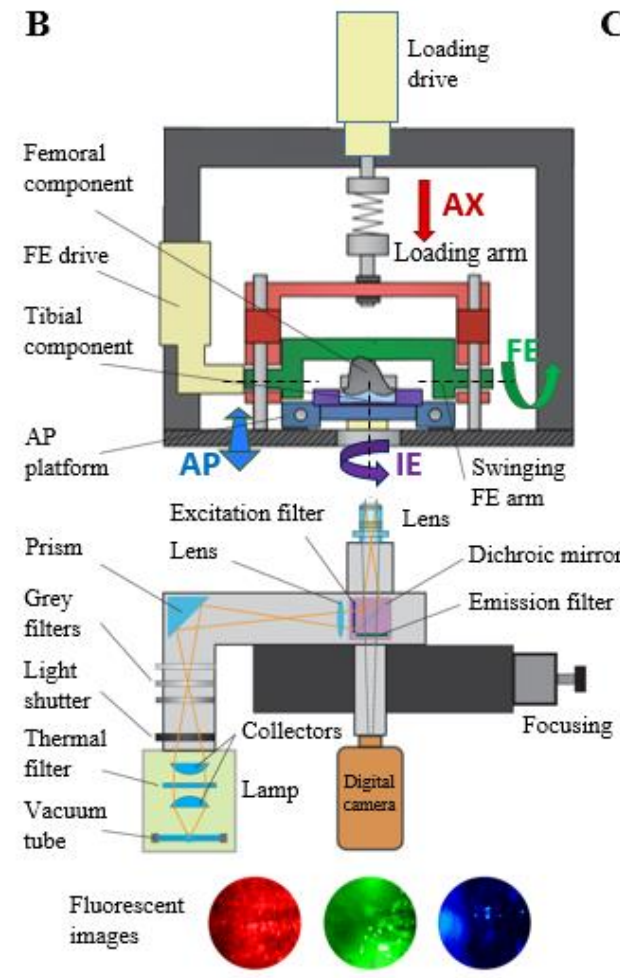

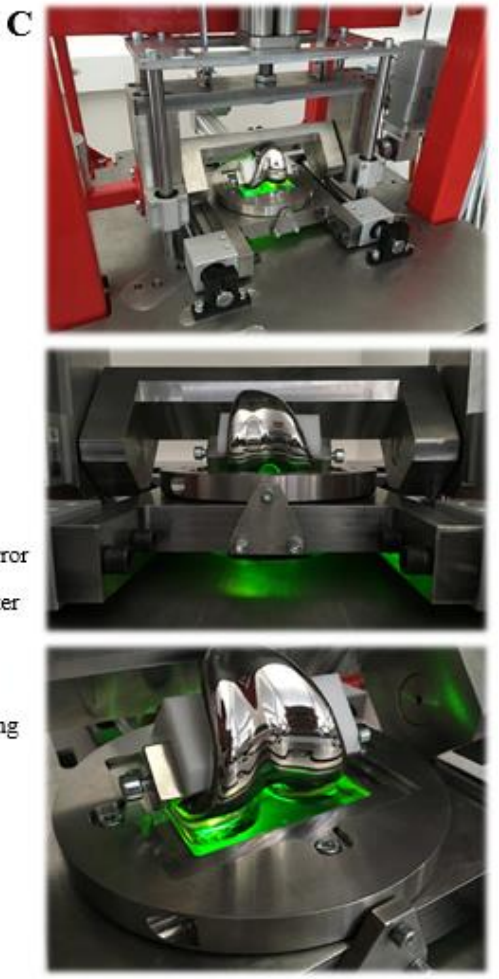

Fig. 1. (A) Knee test rig digital model. (B) Detailed measurement setup. (C) Real appearance of the contact couple under fluorescent illumination (partially edited based on [46],[47]). thickness [51],[52],[53], it features some specific limitations disabling quantitative evaluation in this particular case. The point is that the method is suitable especially for non-reflective materials, e.g. rubbers or polymers. However, the chromium contained in the original femoral component leads to a 
loss of fluorescent intensity, so-called quenching [54]. Moreover, undesired interference fringes arise since the surface is highly reflective, preventing accurate film thickness calibration [55]. Hence, the recorded intensity represents a dimensionless averaged thickness of the layer, allowing to explore general trends and differences between various model lubricants. This is valid due to the proportionality of lubricant layer thickness and emitted intensity [56]. This approach was recently validated upon investigation of hip implants [48].

\subsection{Samples and lubricants}

The contact of original femoral CoCrMo alloy and real-shaped polymer tibial knee components was observed. Tibial plateaus made from UHMWPE could not be used because of their non-transparent nature. Therefore, the original geometry of the insert was obtained using optical scanning and the model was subsequently fabricated by micro-chip machining from poly(methyl)methacrylate (PMMA). The motivation for usage of PMMA comes from similar surface nature compared to UHMWPE. In addition, this material is frequently employed in tribological testing of implants since it has been used as a bone cement, potentially being exposed to rubbing with joint components [57]. Prior to testing, the surface roughness was analyzed with a 3D optical profiler, revealing that the averaged values were comparable for both the tested components, being somewhere between 10 and $50 \mathrm{~nm}$ dependently on the location. Considering the model lubricants, the present study was divided into two parts. At first, the authors concentrated on the comparison of the experimental approach with numerical modeling as presented in Part II [34]. For this purpose, the contact was lubricated by pure mineral oil R834/80 (Paramo, Czech Republic) having a dynamic viscosity $\eta=0.179 \mathrm{~Pa} \cdot \mathrm{s}$ at ambient temperature. Mineral oil is suitable not only because it can be clearly assessed for the numerical model, but also because it naturally emits fluorescence, so there is no need of fluorescent markers [58]. Both lateral and medial compartments were studied while instantaneous oil film intensity was taken at six positions of the contact corresponding to $0 \%, 14 \%, 25 \%, 45 \%, 60 \%$ and $80 \%$ of the applied gait cycle, as is illustrated in Fig. 2A. In order to show repeatability, the experiments were repeated three times on different days for both the compartments and all the locations. 

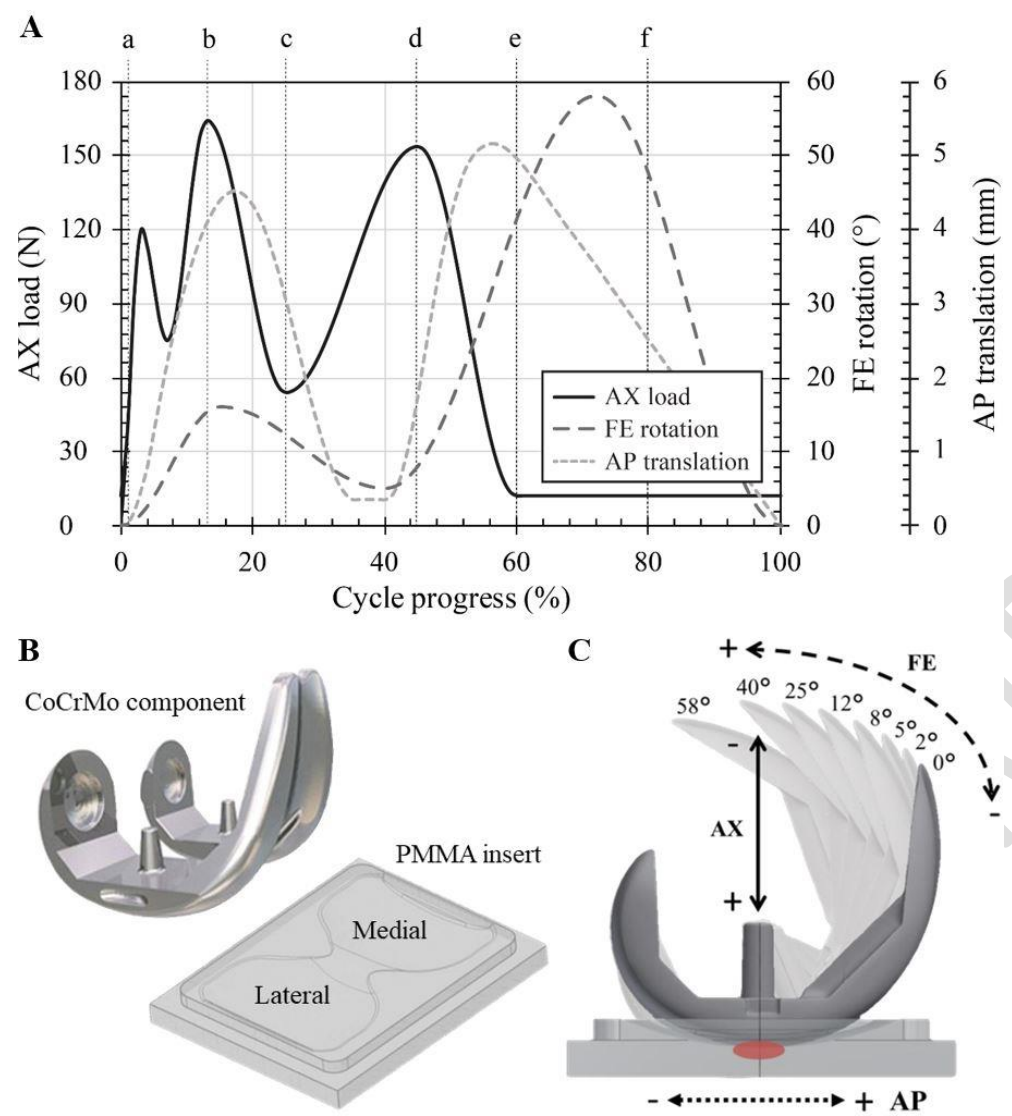

Fig. 2. (A) Course of AX load, FE rotation, AP translation. (B) Detail of the contact components. (C) Illustration of AX, FE, and AP with highlighted contact position. during film formation process. In that case, thirteen different lubricants of various complexity were used while various constituents were fluorescently stained. PBS represented a base medium. The initial experiments were carried out with labelled albumin from bovine serum (A2153, Sigma-Aldrich) based lubricants. A second set was carried out with the fluids containing stained bovine blood $\gamma$-globulin (G5009, Sigma-Aldrich). A third series was realized with labelled HA (Sodium Hyaluronate powder, Contipro). The details about fluorescent labelling may be found in the previous study [48]. Finally, a combined series was realized with the master model liquid, which contained all the three aforementioned constituents stained. The motivation of this test was to confirm the expected film formation based on the observation of individual constituents. PLs (P3556, Sigma-Aldrich) were also considered in this study. However, these were not stained due to very low concentration and very limited ability of staining using commercial products and established procedures. Despite the presence of specific constituents that 
was different in various lubricants, the concentration was kept constant to avoid any distraction due to

fluid composition. Concentrations of albumin, $\gamma$-globulin, HA, and PLs were $24.9 \mathrm{mg}$ per ml, $6.1 \mathrm{mg}$

201

202

203

204

205 per $\mathrm{ml}, 1.49 \mathrm{mg}$ per $\mathrm{ml}$, and $0.34 \mathrm{mg}$ per $\mathrm{ml}$, respectively. This composition reflected the average composition of patients expecting TKA [43][40]. Both, the lateral and the medial compartments were investigated being lubricated by the artificial model fluids mimicking synovial fluid. However, the observation was done exclusively for maximal load, i.e. the load peak which occurs at $14 \%$ of the cycle (point (b), see Fig. 2A) due to the necessity to move the optical system when focusing on other positions and the excessive amounts of lubricant required. Repeatability of the system was studied using simple albumin and simple $\gamma$-globulin solutions, however, not with complex solutions because of the excessive amounts of lubricant required. Nevertheless, due to the superposition character of the study and due to the strict compliance with the laboratory protocol, we believe the generated data is representative. The information about the concentration of specific constituents together with the observed location is summarized in Tab. 1.

According to laboratory protocol, stained and non-stained constituents were prepared separately. Prior further use, these were stored frozen at $-22{ }^{\circ} \mathrm{C}$. The solutions were then thawed naturally being exposed to ambient temperature for 1.5 hours before the test started. After natural thawing under ambient temperature, stained and non-stained constituents were mixed together by mild shaking. After each experiment, the lubricant was discarded. Both the test specimens (femoral component, tibial insert) were carefully cleaned following the established protocol [48].

Tab. 1. An overview of the test lubricants (partially modified based on [48].

\begin{tabular}{|c|c|c|c|c|c|}
\hline No. & Stained constituent & Non-stained constituent & Total concentration & Dynamic viscosity & Observed location \\
\hline 1. & Mineral oil & - & - & $179 \mathrm{mPa} \cdot \mathrm{s}$ & $\mathrm{a}, \mathrm{b}, \mathrm{c}, \mathrm{d}, \mathrm{e}, \mathrm{f}$ \\
\hline 2. & Albumin $(24.9 \mathrm{mg} / \mathrm{ml})$ & - & $24.9 \mathrm{mg} / \mathrm{ml}$ & $1.7 \mathrm{mPa} \cdot \mathrm{s}$ & $\mathrm{b}$ \\
\hline 3. & Albumin $(24.9 \mathrm{mg} / \mathrm{ml})$ & $\gamma$-globulin $(6.1 \mathrm{mg} / \mathrm{ml})$ & $31 \mathrm{mg} / \mathrm{ml}$ & $2 \mathrm{mPa} \cdot \mathrm{s}$ & $\mathrm{b}$ \\
\hline 4. & Albumin $(24.9 \mathrm{mg} / \mathrm{ml})$ & $\begin{array}{c}\gamma \text {-globulin }(6.1 \mathrm{mg} / \mathrm{ml}) \\
\text { HA }(1.49 \mathrm{mg} / \mathrm{ml})\end{array}$ & $32.49 \mathrm{mg} / \mathrm{ml}$ & $3.2 \mathrm{mPa} \cdot \mathrm{s}$ & $\mathrm{b}$ \\
\hline 5. & Albumin $(24.9 \mathrm{mg} / \mathrm{ml})$ & $\gamma$-globulin $(6.1 \mathrm{mg} / \mathrm{ml})$ & $32.83 \mathrm{mg} / \mathrm{ml}$ & $3.3 \mathrm{mPa} \cdot \mathrm{s}$ & $\mathrm{b}$ \\
\hline
\end{tabular}




\begin{tabular}{|c|c|c|c|c|c|}
\hline & & $\begin{array}{l}\text { HA }(1.49 \mathrm{mg} / \mathrm{ml}) \\
\text { PLs }(0.34 \mathrm{mg} / \mathrm{ml})\end{array}$ & & & \\
\hline 6. & $\gamma$-globulin $(6.1 \mathrm{mg} / \mathrm{ml})$ & - & $6.1 \mathrm{mg} / \mathrm{ml}$ & $0.5 \mathrm{mPa} \cdot \mathrm{s}$ & $b$ \\
\hline 7. & $\gamma$-globulin $(6.1 \mathrm{mg} / \mathrm{ml})$ & Albumin $(24.9 \mathrm{mg} / \mathrm{ml})$ & $31 \mathrm{mg} / \mathrm{ml}$ & $2 \mathrm{mPa} \cdot \mathrm{s}$ & $\mathrm{b}$ \\
\hline 8. & $\gamma$-globulin $(6.1 \mathrm{mg} / \mathrm{ml})$ & $\begin{array}{c}\text { Albumin }(24.9 \mathrm{mg} / \mathrm{ml}) \\
\text { HA }(1.49 \mathrm{mg} / \mathrm{ml})\end{array}$ & $32.49 \mathrm{mg} / \mathrm{ml}$ & $3.2 \mathrm{mPa} \cdot \mathrm{s}$ & $\mathrm{b}$ \\
\hline 9. & $\gamma$-globulin $(6.1 \mathrm{mg} / \mathrm{ml})$ & $\begin{array}{c}\text { Albumin }(24.9 \mathrm{mg} / \mathrm{ml}) \\
\text { HA }(1.49 \mathrm{mg} / \mathrm{ml}) \\
\text { PLs }(0.34 \mathrm{mg} / \mathrm{ml})\end{array}$ & $32.83 \mathrm{mg} / \mathrm{ml}$ & $3.3 \mathrm{mPa} \cdot \mathrm{s}$ & $\mathrm{b}$ \\
\hline 10. & HA $(1.49 \mathrm{mg} / \mathrm{ml})$ & PLs $(0.34 \mathrm{mg} / \mathrm{ml})$ & $1.83 \mathrm{mg} / \mathrm{ml}$ & $2.2 \mathrm{mPa} \cdot \mathrm{s}$ & b \\
\hline 11. & HA $(1.49 \mathrm{mg} / \mathrm{ml})$ & $\begin{array}{c}\text { Albumin }(24.9 \mathrm{mg} / \mathrm{ml}) \\
\text { PLs }(0.34 \mathrm{mg} / \mathrm{ml})\end{array}$ & $26.73 \mathrm{mg} / \mathrm{ml}$ & $3.2 \mathrm{mPa} \cdot \mathrm{s}$ & b \\
\hline 12. & HA $(1.49 \mathrm{mg} / \mathrm{ml})$ & $\begin{array}{c}\gamma \text {-globulin }(6.1 \mathrm{mg} / \mathrm{ml}) \\
\text { PLs }(0.34 \mathrm{mg} / \mathrm{ml})\end{array}$ & $7.93 \mathrm{mg} / \mathrm{ml}$ & $3 \mathrm{mPa} \cdot \mathrm{s}$ & $b$ \\
\hline 13. & HA (1.49 mg/ml) & $\begin{array}{l}\text { Albumin }(24.9 \mathrm{mg} / \mathrm{ml}) \\
\gamma \text {-globulin }(6.1 \mathrm{mg} / \mathrm{ml}) \\
\text { PLs }(0.34 \mathrm{mg} / \mathrm{ml})\end{array}$ & $32.83 \mathrm{~m}$ & $3.3 \mathrm{mPa} \cdot \mathrm{s}$ & $b$ \\
\hline 14. & $\begin{array}{c}\text { Albumin }(24.9 \mathrm{mg} / \mathrm{ml}) \\
\gamma \text {-globulin }(6.1 \mathrm{mg} / \mathrm{ml}) \\
\text { HA }(1.49 \mathrm{mg} / \mathrm{ml})\end{array}$ & PLs $(0.34 \mathrm{mg} / \mathrm{ml})$ & $32.83 \mathrm{mg} / \mathrm{ml}$ & $3.3 \mathrm{mPa} \cdot \mathrm{s}$ & $\mathrm{b}$ \\
\hline
\end{tabular}

\subsection{Experimental conditions}

222 Since one of the goals of this study was to evaluate and visualize film formation under realistic transient loading and kinematic conditions, the parameters of the gait cycle were set following ISO 14243-3 standard [31] for AP translation and AX load. IE rotation was fixed as it varies in only a limited range throughout the cycle $\left(0^{\circ}\right.$ to $\left.5 \cdot 2^{\circ}\right)$. Following the mechanical properties of the components $\left(\mathrm{E}_{\mathrm{CoCrMo}}=240\right.$ $\mathrm{GPa}, v_{\mathrm{CoCrMo}}=0.29, \mathrm{E}_{\mathrm{PMMA}}=3.5 \mathrm{GPa}$, and $\left.v_{\mathrm{PMMA}}=0.34\right)$ the axial load was proportionally lowered (varying from $15 \mathrm{~N}$ to $175 \mathrm{~N}$ ) compared to ISO standard in order to obtain a contact pressure at maximum load comparable to CoCrMo/UHMWPE contact pairing as UHMWPE has seven-fold lower elastic modulus than PMMA. Thus, the maximum pressure was between 25 and $35 \mathrm{MPa}$ for lateral and medial compartment, respectively. These values are in accordance to those presented in Part II [34], as well as in other literature [59],[60]. Range of FE rotation was between $0^{\circ}$ (initial position) and $58^{\circ}$ 
(maximally deflected position). AP translation ranged from $0 \mathrm{~mm}$ (initial position) to $-5.2 \mathrm{~mm}$ (maximally shifted position). The tests were performed at $1 \mathrm{~Hz}$ frequency and ambient temperature $\left(23^{\circ} \mathrm{C}-25^{\circ} \mathrm{C}\right)$

The plotted film thickness in results section represents an average value throughout the contact zone highlighted in the recorded images. The length of the tests was set to $30 \mathrm{~s}$ as it was previously shown to be adequate to clarify the interaction of the constituents and to get contact images of sufficient quality and resolution. At the end, an extra time test was conducted with complex model fluid no. 14. In that case, the experiment was run five times while $30 \mathrm{~s}$ were recorded within the first test. Then, the experiment was restarted, while the 30 to $60 \mathrm{~s}$ period was recorded. Thus the second test lasted $60 \mathrm{~s}$, however, only $30 \mathrm{~s}$ were recorded. The same for interval 60 to $90 \mathrm{~s}, 90$ to $120 \mathrm{~s}$ and 120 to $150 \mathrm{~s}$, respectively. Therefore, the overall duration of the time test was $450 \mathrm{~s}$. One of the benefits of this test is that continuity of the data is considered as a proof of measurement repeatability.

\section{Results}

\subsection{Mineral oil}

Initial tests were carried out using mineral oil enabling to compare the experimental measurement with the developed numerical model presented in Part II [34]. Both the lateral and the medial compartments were investigated while six specific locations throughout the cycle were observed (see Fig. 2A). Results of fluorescent intensity (experiment) and dimensionless specific film thickness (simulation), which represents overall lubricant gap height averaged over the contact domain [34], are displayed in Fig. 3A. Apparently, there is a good agreement of both approaches. Qualitatively, the measured data corresponded to those predicted by the model in most locations ((b) to (f)). The only considerable difference is observed at point (a) where AX load and AP translation exhibit a substantial transition at the same time, possibly leading to some fluctuations in experimental results. Further small disagreement may be identified for medial compartment between points (e) and (f). While simulation showed slight improvement of the lubricant layer in this phase, the experiment exhibited a drop of the film. This behavior is attributed to the fact that FE motion reaches the maximum between these points and the motion is being reversed which may lead to partial removal of the lubricant layer. This phenomenon 
may be hardly simulated. Further, the contact zone on medial condyle moves and changes its shape considerably between (e) and (f), as can be seen in Fig. 3B. Focusing on the development of the film formation during the cycle, the lateral compartment exhibits sudden jump at the beginning of the experiment compared to medial one. During the rest of the cycle, the film thickness is quite comparable with the exception of point (e) where medial compartment showed enhanced film thickness. Qualitatively, this also agrees very well with the numerical study (see Fig. 3A). As is shown in Fig. 3A, the repeatability of the data was excellent for the medial condyle and standard deviations may be only hardly distinguished for most of the locations. In the case of the lateral compartment, a slight variance was observed at the beginning of the cycle, while this stage is associated with transition from maximal to minimal FE rotation together with swift from minimum to maximum AX load. Corresponding images of the observed areas with highlighted contact zones are presented in Fig. 3B. It should be noted that the sizes of the contact are not proportional to load in all the locations due to varying radii of the lateral and the medial compartments along sagittal and frontal axes. In some images, the contact area cannot be clearly recognized as these pictures are taken during the experiment. The positions and shapes of contact areas were determined based on the appearance of the static image taken at each specific phase. The differences of the contact areas underline the differences in the load of both the compartments due to geometry. 

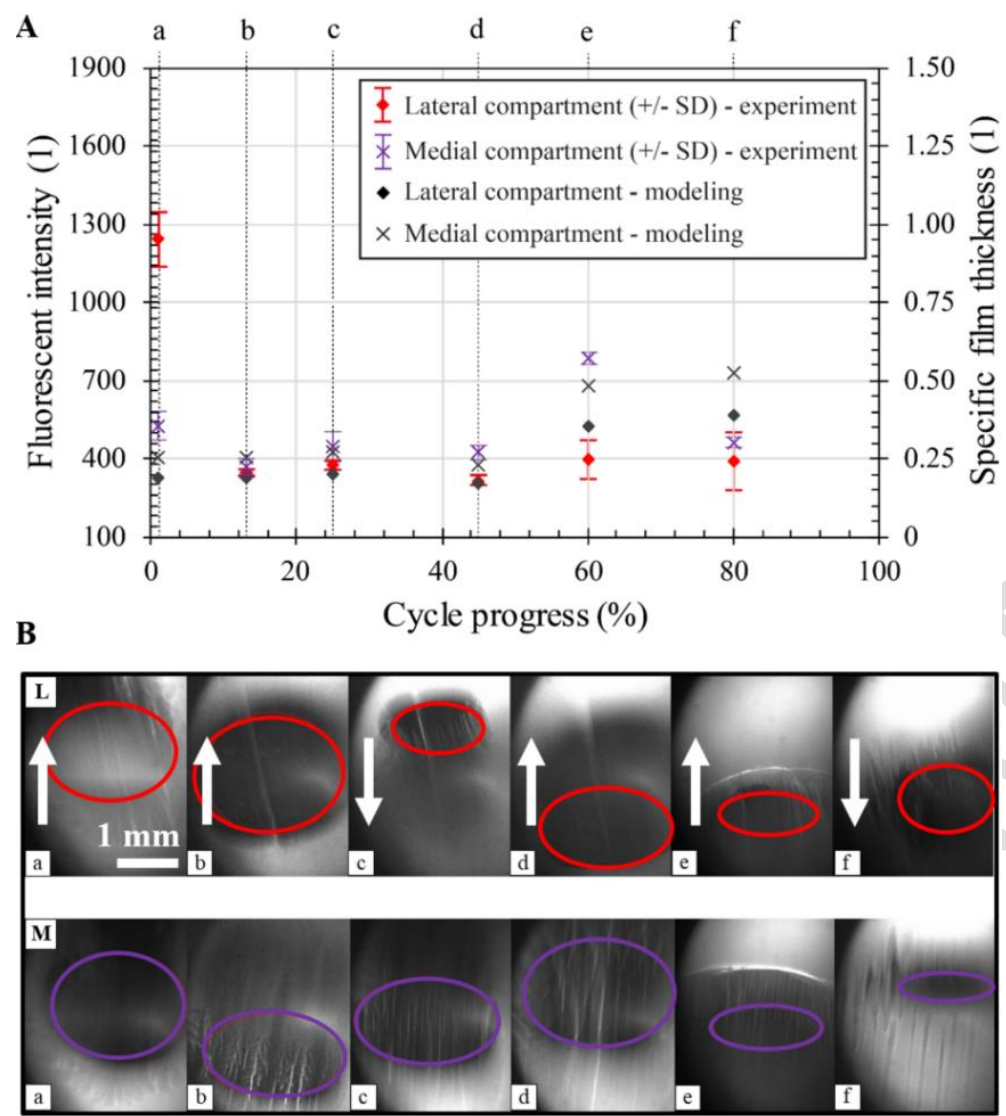

Fig. 3. (A) Oil film intensity for both the lateral and the medial compartments at specific locations throughout the cycle. (B) Fluorescent images with highlighted contact area for lateral (top) and medial (bottom) compartments at the locations. The white arrows in the top row of contact images (B) indicate lubricant inlet into the contact (upward/downward orientation is given by a combination of FE rotation and AP translation).

\subsection{Albumin-based fluids}

Further, an analysis of model synovial fluid lubricants was conducted. The first set of the tests was carried out with albumin-based lubricants. The results for lateral compartment are displayed in Fig. 4A. It is evident that addition of $\gamma$-globulin and HA did not enhance the film formation. However, when all

291 the constituents including PLs were considered, the film was the thickest. Overall, similar tendency was 292 observed for all the tested lubricants with initial gradual increase and stabilization after $15-20 \mathrm{~s}$. An 293 increase of film thickness can be clearly recognized when focusing on the contact images in Fig. 4C. In 
the figure, an interesting phenomenon leading to enhancement of the layer towards positive AP direction may be observed. This is associated with large protein clusters near the contact boundary. In the video of the test, it could be clearly observed that the femoral implant rolls up the lubricant in the direction of AP motion. Different behavior was observed for medial compartment (Fig. 4B). In that case, simple albumin and the mixture of the proteins showed a slight increase with subsequent decrease and stabilization. However, when HA and HA with PLs were added, the film dropped immediately after the beginning of the experiment. This was accompanied by the removal of the protein agglomerations out of the contact zone, as is apparent from Fig. 4D for time $t=10 \mathrm{~s}$ and later. Overall, a thicker lubricant layer was detected for lateral compartment, independently of the test lubricant.
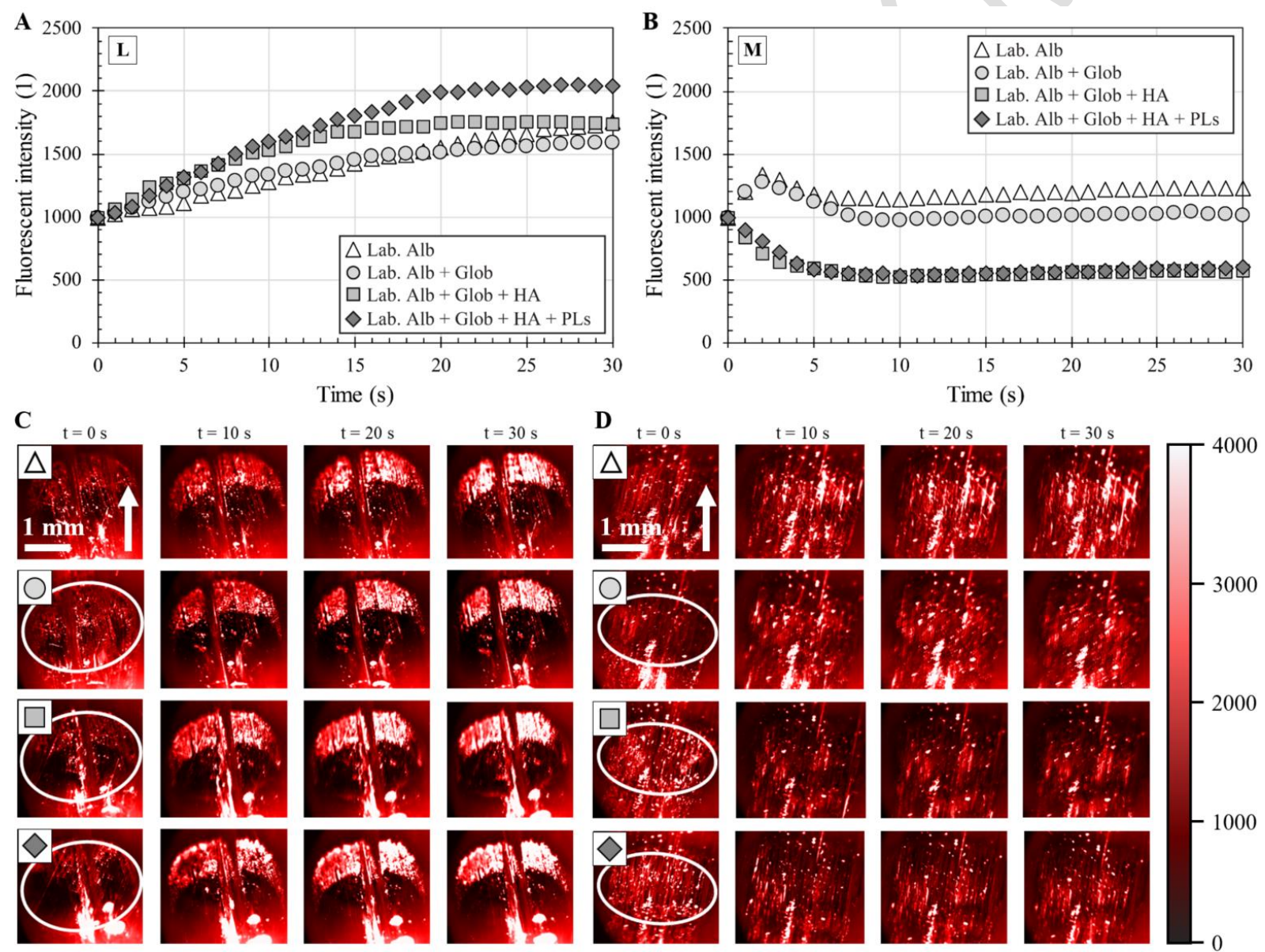

Fig. 4. (A) Evolution of albumin-based fluorescent intensity versus time for lateral and (B) medial compartment at point (b). (C) Fluorescent images for lateral and (D) medial compartment (the symbols 


\section{3 r-globulin-based fluids}

310 Subsequent tests were realized using the lubricants on $\gamma$-globulin basis. The results of film intensities 311 are shown in Fig. 5A and 5B. As can be seen, these fluids generally exhibited much thinner film 312 compared to albumin solutions. The graphs contain the scaled details, showing that the film gradually 313 increased in the case of the lateral condyle (Fig. 5A). As for albumin solutions above, an increase of 314 film is attributed to grouping of the proteins near contact boundary, as is displayed in Fig. 5C. Focusing 315 on the medial compartment, very limited film formation was observed, as is displayed in Fig. 5B and 5D. Negligible fluctuations of the layer attributed to repeated entrapment and release of the proteins in and out the contact zone can be observed in Fig. 5D.
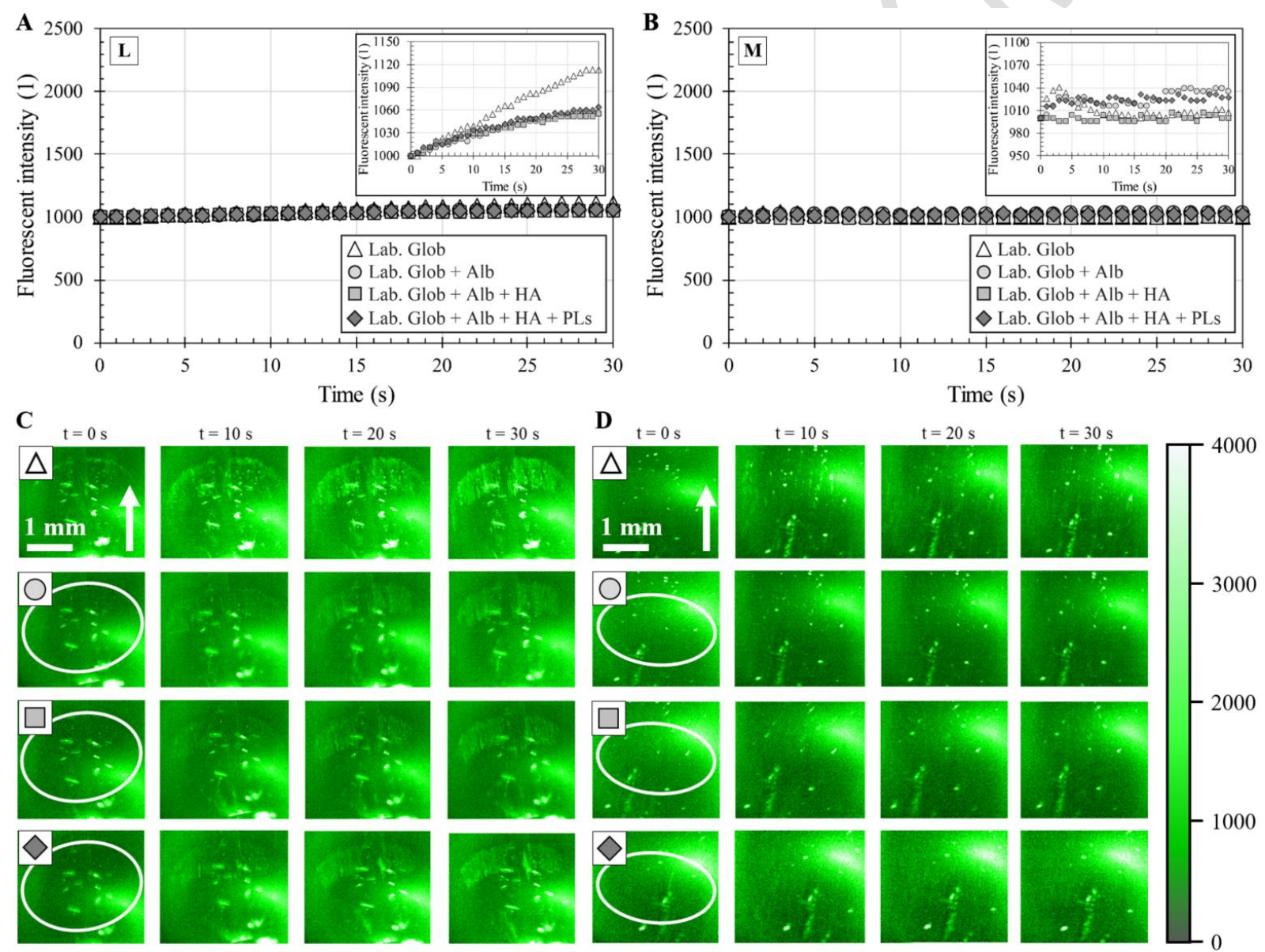

Fig. 5. (A) Evolution of $\gamma$-globulin-based lubricant film intensity versus time for lateral and (B) medial compartment at point (b). The details in top right corners are the same graphs with scaled y-axis. (C)

Fluorescent images for lateral and (D) medial compartment (the symbols in top left corner refer to the graphs above). The white arrows in the top left contact images (C), (D) indicate lubricant inlet into the 


\subsection{Hyaluronic acid-based fluids}

326 HA is considered to be strongly supportive in terms of lubrication performance. Nevertheless, very

327 limited ability to form stable lubricating layer of HA was recently observed for hip replacements [61].

328 In general, intensity of HA film is comparable to those for $\gamma$-globulin (Fig. 6A and 6B). Focusing on the

329 lateral compartment, only the mixture of HA and albumin caused slight increase of HA layer. However,

330 this can hardly be recognized on the contact images (Fig. 6C), indicating the effect was limited. In the

331 case of the medial condyle (Fig. 6B and 6D) simple HA showed a continuous development, which

332 corresponds to the contact images of the top row in Fig. 6D. When comparing both compartments, it is

333 evident that HA shows a stronger tendency to be entrapped within medial compartment pointing on the

334 sensitivity to load/contact pressure.
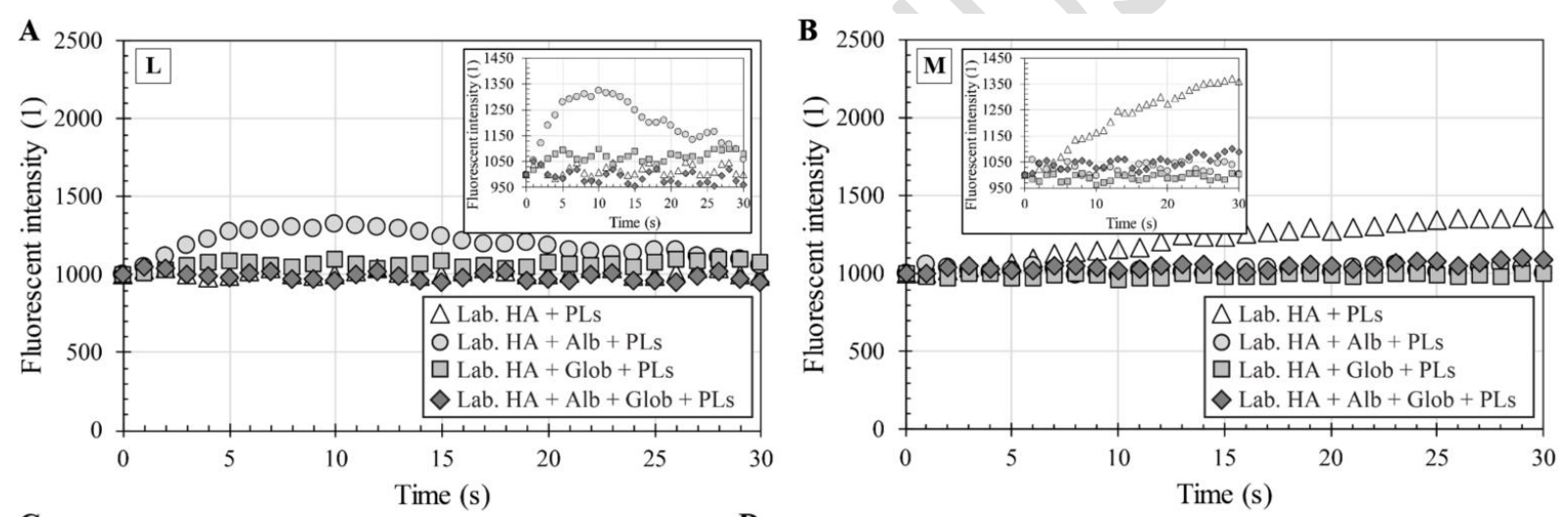

C $\quad t=0 s$

$\mathrm{t}=20 \mathrm{~s}$

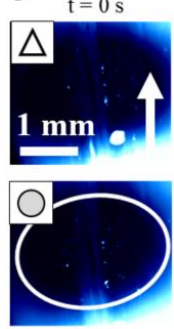

$t=10 s$
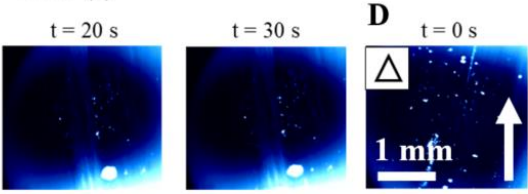

$\mathrm{t}=10 \mathrm{~s}$
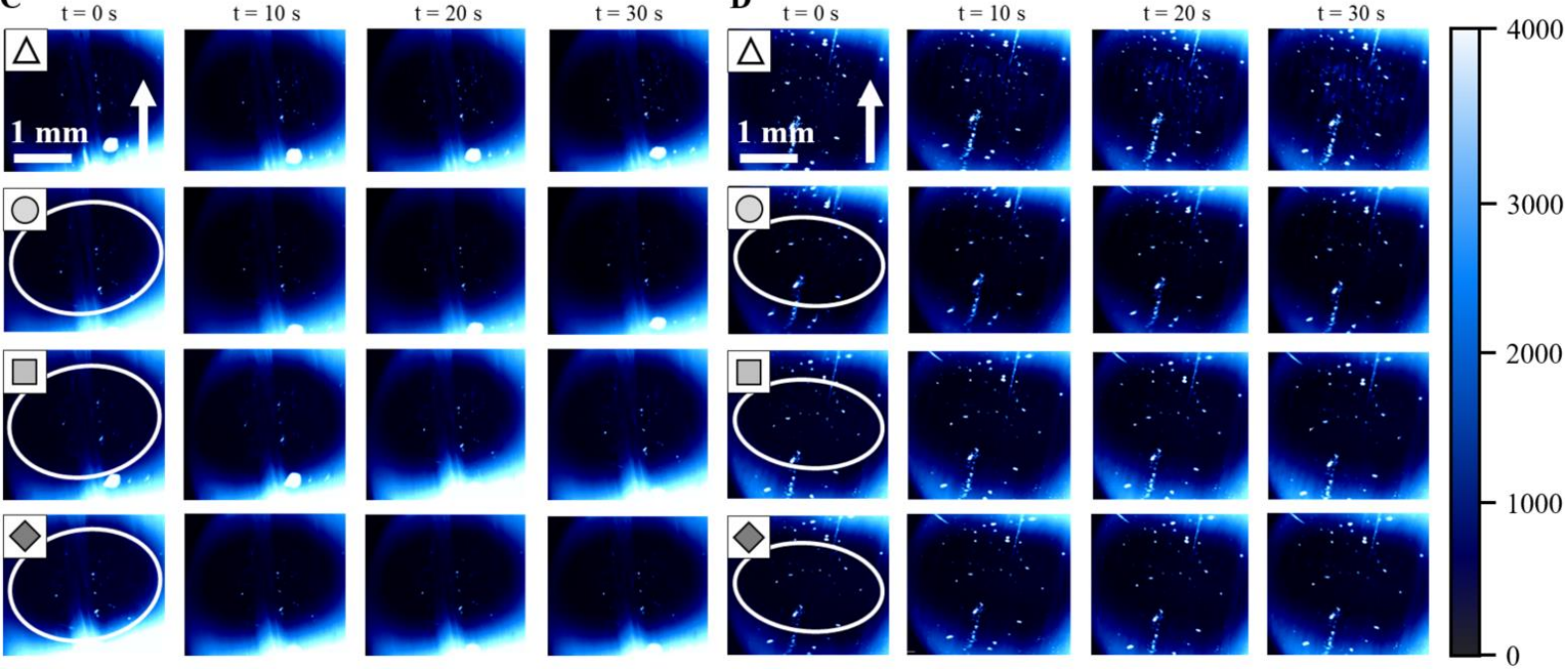

Fig. 6. (A) Evolution of HA-based fluid film intensity versus time for lateral and (B) medial compartment at point (b). The details in top right corners are the same graphs with scaled y-axis. (C)

Fluorescent images for lateral and (D) medial compartment (the symbols in top left corner refer to the 
graphs above). The white arrows in the top left contact images (C), (D) indicate lubricant inlet into the contact.

\subsection{Complex solutions}

343 Finally, results for three different complex solutions with labelled albumin, $\gamma$-globulin, and HA were compared to those for the liquid containing all the aforementioned constituents to be stained at the same time (master lubricant). This experiment is supposed to reveal the film formation mechanism by comparison of the trend for the master curve with the trends for the individual curves. As shown for lateral compartment (Fig. 7A and 7C), the overall tendency was in satisfactory compliance with the development of albumin-based complex fluid. This indicates a fundamental role of albumin in film formation process. The dominant presence of albumin can be clearly recognized when comparing top and bottom row of images in Fig. 7C. The lower intensity of the master curve compared to the albumin curve can be attributed to emission reabsorption, while the emitted intensity of the first fluorescent marker further excites another marker [62]. If the reabsorption would not take an action, the total fluorescent emission of the master curves would be higher. In preliminary tests dealing with the estimation of reabsorption level in a simplified ball-on-disc setup, it was found that combination of the markers used in the present study (Rhodamine-B-isothiocyanate and Fluorescein-isothiocyanate) led to a drop of intensity in the range from $25 \%$ to $40 \%$ for the expected thicknesses (several hundreds of nm to units of $\mu \mathrm{m})$. Therefore, it is assumed that without the presence of this reabsorption phenomenon, the maximum intensity for the lateral condyle (Fig. 7A) would be somewhere between 2200 and 2500 . Regarding the medial compartment (Fig. 7B), the expected maximum intensity, if reabsorption could be eliminated, is in the range from 1200 to 1400. other two curves for $\gamma$-globulin and HA based solutions. Thus, it can be estimated that the two constituents contribute to enhanced lubrication of the medial condyle despite the albumin drop. Nevertheless, the thickness of the lubricating layer is more than double for lateral compartment, indicating more favorable contact conditions, potentially positively affecting wear resistance. 

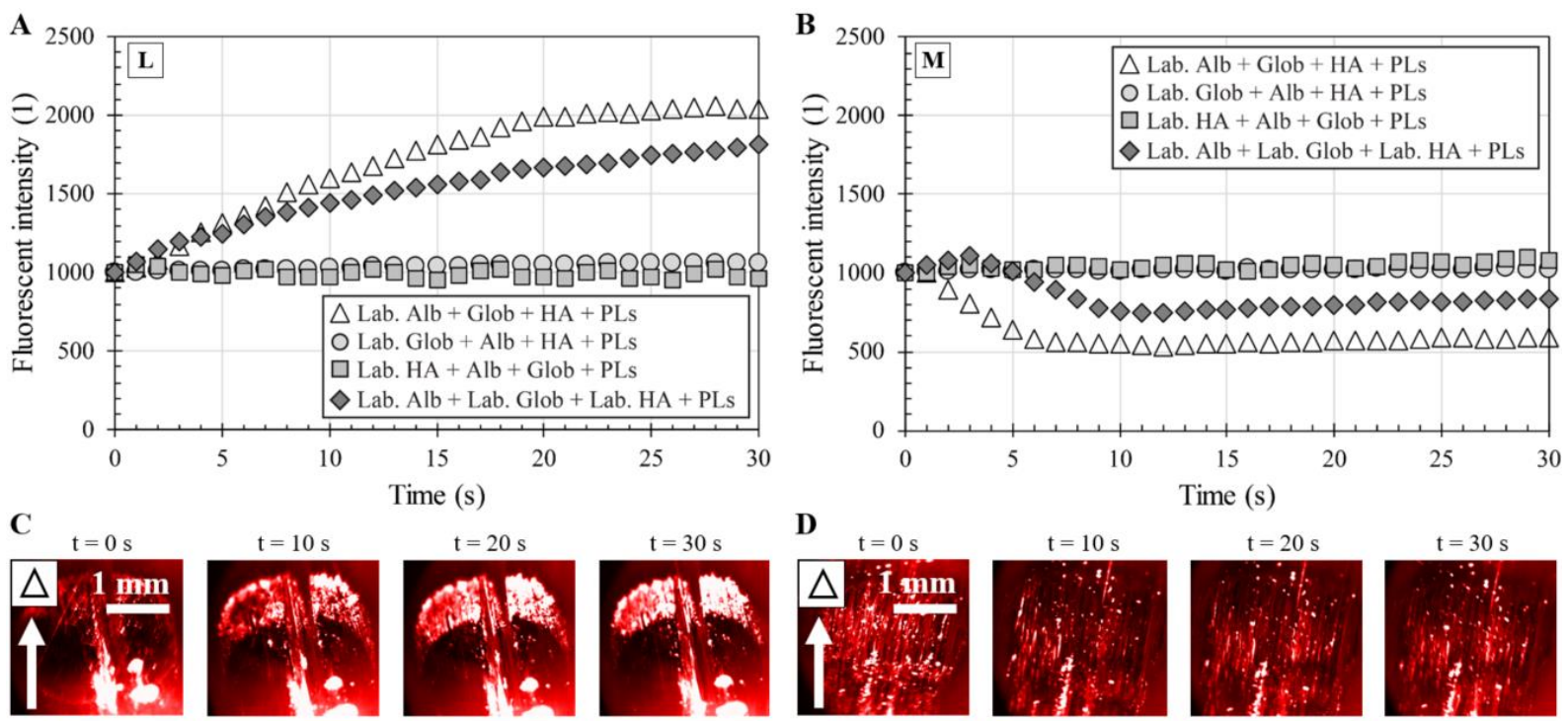

$\mathrm{t}=10 \mathrm{~s}$

$t=20 s$
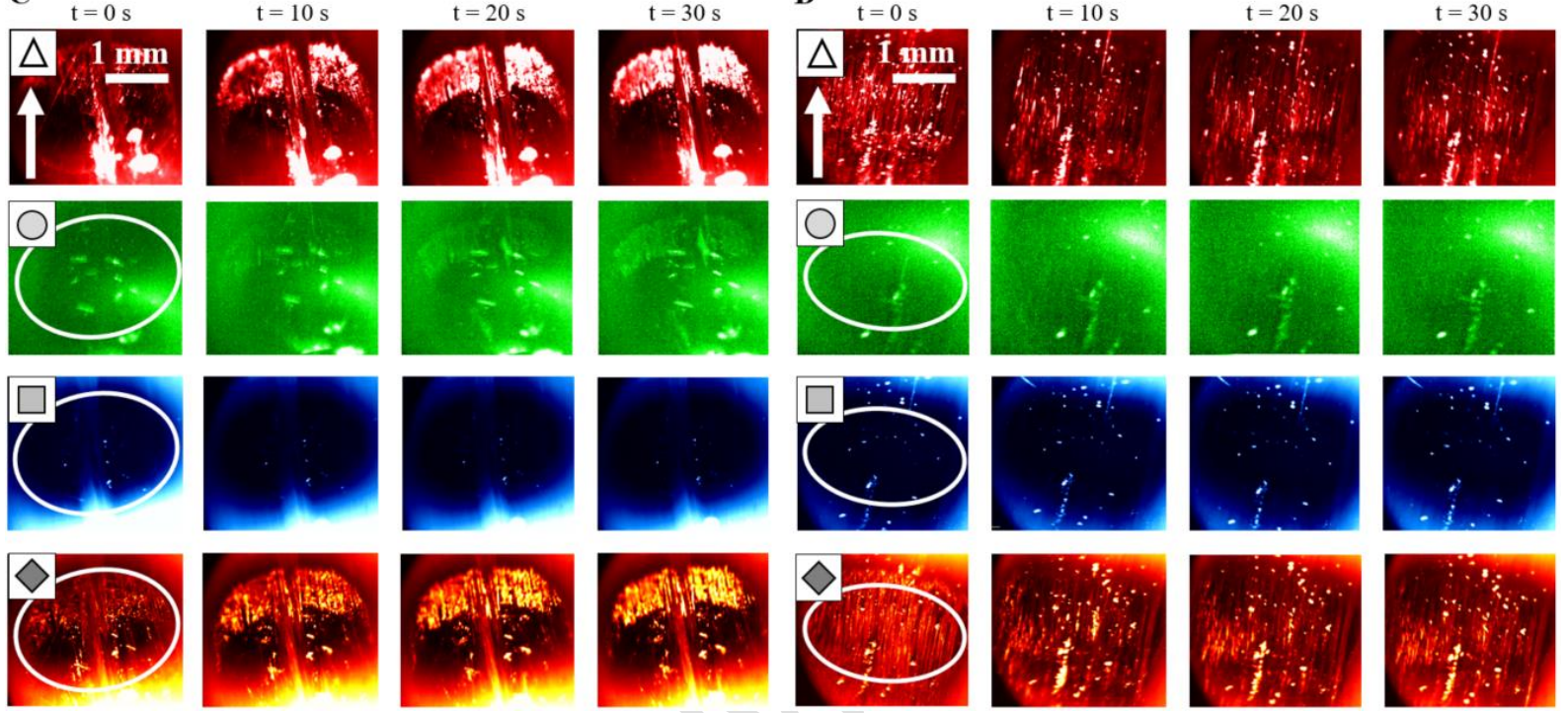

Fig. 7. (A) Evolution of complex fluorescent intensity versus time for various complex model fluids

for lateral and (B) medial compartment. (C) Fluorescent images for lateral and (D) medial compartment (the symbols in top left corner refer to the graphs above). The white arrows in the top left contact images (C), (D) indicate lubricant inlet into the contact.

In order to reveal the behavior of synovial fluid film in a longer time frame, cumulative tests were performed while only $30 \mathrm{~s}$ of the experiment were recorded as explained in section 2.3 . Once the first test (30 s) finished, the contact was kept loaded for five minutes while neither FE rotation nor AP translation were applied. After the break, the experiment was restarted lasting $60 \mathrm{~s}$ while the 30 to $60 \mathrm{~s}$ period was recorded. This approach was repeated five times to get a cumulative data for $450 \mathrm{~s}$ of swinging. As there was no unloading phase, this experiment corresponded to an accumulation of a 30, $60,90,120,150$ s lasting walk and five minutes of still stand between the steps. As can be seen in Fig. $8 \mathrm{~A}$ and $8 \mathrm{~B}$, the film increased during the first part of the test for lateral condyle. However, longer time 

phase was accompanied by quite stable behavior as can be seen for the contact shown in Fig. 8C.

$\mathbf{A}$

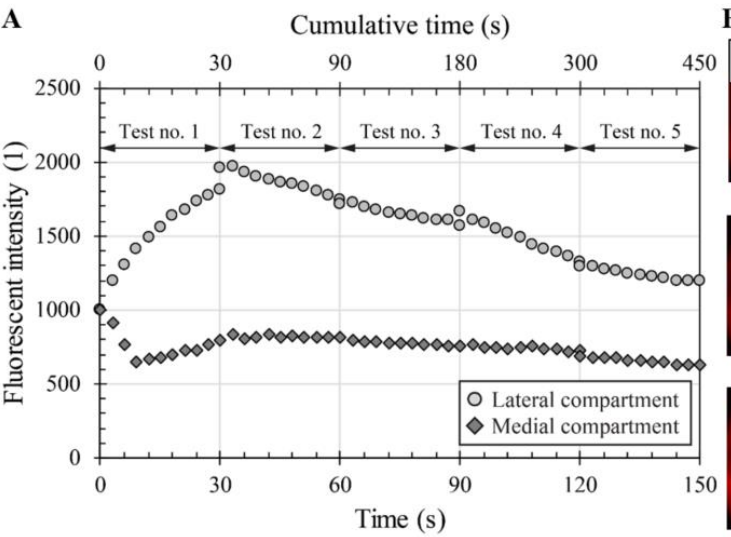
B $\quad \mathrm{t}=0 \mathrm{~s}$

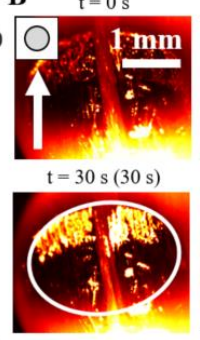

$\mathrm{t}=60 \mathrm{~s}(90 \mathrm{~s})$
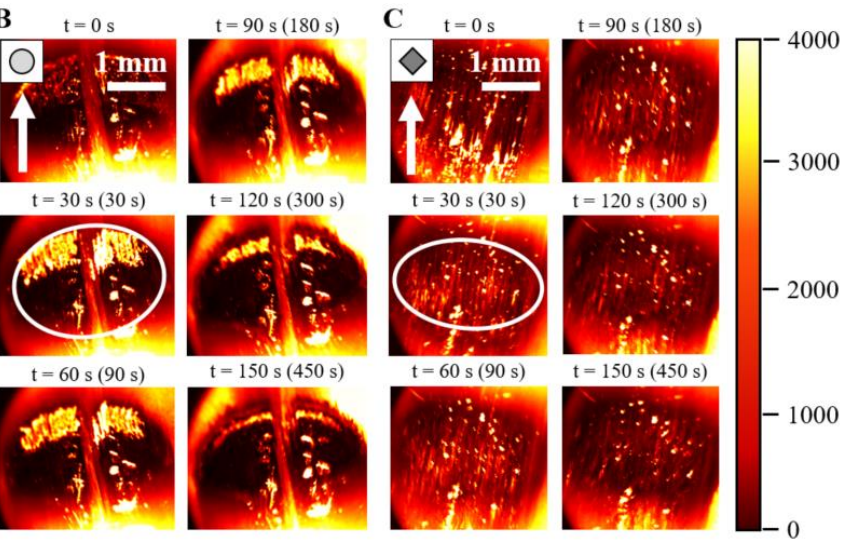

Fig. 8. (A) Time test - development of complex lubricant film intensity versus time for lateral and

medial compartment. (B) Fluorescent images for lateral and (C) medial compartment (the symbols in top left corner refer to the graph (A)). The white arrows in the top left contact images (B), (C) indicate lubricant inlet into the contact.

\section{Discussion}

\subsection{General discussion}

The contribution focused on the assessment of lubrication mechanisms in TKA, focusing on the behavior of specific constituents contained in synovial liquid. The main benefits come from analyzing both the TKA separately and ability to distinguish dominant constituents of synovial fluid and to describe its mutual interactions. Concentrating on albumin protein, positive influence on lubricant film was observed when all the studied constituents were considered for the lateral compartment. On the contrary, opposite influence was reported for the medial condyle, indicating sensitivity of the layer on load. Albumin also showed a strong tendency to agglomerate, creating protein clusters. Focusing on $\gamma$ globulin solutions, these exhibited very thin lubricant layer for both the compartments. Despite the lower 
agglomerations formed along AP direction. Similar behavior was also observed for HA which only hardly formed a stable lubricating layer.

To evaluate the lubrication mechanism, protein adsorption has to be taken into account. The ability of the proteins to adsorb on the rubbing surfaces is crucial in order to form boundary lubricating film. Protein adsorption on solid surfaces is a complex phenomenon combining hydrophobic, hydrogenbonding, and electrostatic interactions [63]. Based on the literature, it is assumed that albumin and $\gamma$ globulin exhibit stronger adsorption to hydrophobic surfaces [64]. This is confirmed by the present observation. As PMMA is highly hydrophobic [65], the proteins tend to be adsorbed as can be clearly seen in contact images in Fig. 7C and 7D. Focusing on the specific proteins, its primary structure has to be taken into account. While albumin is dominantly presented in an $\alpha$-helix form, $\gamma$-globulin has a $\beta$ sheet form. Based on recent observation, it is assumed that $\beta$-sheet exhibits a stronger adsorption onto rubbing surfaces while $\alpha$-helix forms lubricating film of low shearing resistance, contributing to lower friction between the surfaces [66],[67],[68]. Stronger adsorption of $\gamma$-globulin is also expected for the femoral component of the TKA which is considered to be neither hydrophobic nor hydrophilic. Nevertheless, $\gamma$-globulin showed more pronounced connection to CoCr surface compared to albumin [69]. It must be emphasized that all the above information based on the particular investigations seem to be in accordance with the present observation.

Assuming the behavior of individual constituents in model synovial fluid, an illustrative lubrication model of the knee implant is proposed and is visualized in Fig. 9. It should be highlighted that the model is based on the detailed observation of the video records of the experiment. It could not be established only based on the images of the contact zones presented in the paper. Thereby, we suggest that the relative motion of the opposing bodies leads to strong adsorption of thin, stable and uniform $\gamma$ globulin film on the contacting surfaces. This is supported by the clusters of $\gamma$-globulin which were found to move simultaneously with the movement of the femoral component, indicating adsorption to the metal surface. Further $\gamma$-globulin agglomerations remained at the same spot throughout the experiment which confirms the adsorption on the stationary PMMA insert. Moreover, referring to the video of the experiment, simple HA with PLs moved in a slightly chaotic way when examined alone despite the comparable intensity to $\gamma$-globulin (Fig. 5 versus Fig, 6). The film was apparently stabilized 
when $\gamma$-globulin was added to the fluid. This point is supported by Yarimitsu et al [70], who observed improved HA adsorption when it was mixed together with $\gamma$-globulin. Very low ability of adsorption of sodium hyaluronate (salt form of hyaluronic acid) on polymer substrate was observed also by Serro et al [33]. Therefore, it is assumed that $\gamma$-globulin layer is reinforced by the molecules of HA and PLs as it was discussed that HA exhibits substantially stronger interaction with $\gamma$-globulin compared to albumin [70] and it is well known that HA and PLs tend to interact. Thus, it is suggested that $\gamma$-globulin creates a boundary lubricating layer. However, because of $\beta$-sheet structure and structure of HA, internal adhesive forces within the layer are not sufficient to enable continuous growth of the layer. Hence, the further increase of film thickness is attributed exclusively to albumin which has a good ability to be attached to the boundary layer and its $\alpha$-helix creates strong mutual bonds, enhancing the lubricating film. This mechanism is partially disrupted in the case of the medial compartment. In that case, the film formation is limited, indicating the importance and sensitivity of the film to the load. As described in chapter 2.3, the difference in contact pressure considering both the compartments is around 5-10 MPa which is equal to $15 \%$ to $30 \%$ of the maximum load of the lateral compartment. While $\gamma$-globulin and HA seem to be resistive against the higher load (simple HA even increases, see Fig. 6B), the albumin layer is disrupted, leading to decrease of the lubricating film, as is shown in Fig. 4B. The film disruption is thus assumed to be related to (a) thinner unstable film at medial compartment and (b) increased portion of the applied load. Such a load difference apparently leads to worse lubrication conditions, which may contribute to a reduced service live of the medial compartment. Although it is well known that wear is influenced by more factors than only lubrication, it is suggested that insufficient lubrication contributes for elevated wear of the medial compartment, which is eventually responsible for shorter implant service life. This statement is supported by our clinical observation during revising surgeries, revealing the medial compartment to be generally more damaged compared to the lateral one. It also agrees with the findings reported in literature [71],[72]. The assumption about the negative effect of elevated load at medial compartment is further supported by investigations of O'Brien et al. [73], who have shown that increasing contact pressure may result in increased XPE wear. The authors further pointed out at some limitations of simplified pin-on-disk testing, which highlights the importance of realistic geometry and applied conditions applied in the present study. Nevertheless, it should be noted that wear is influenced 

seems to be an important contributing factor, which definitely cannot be neglected.

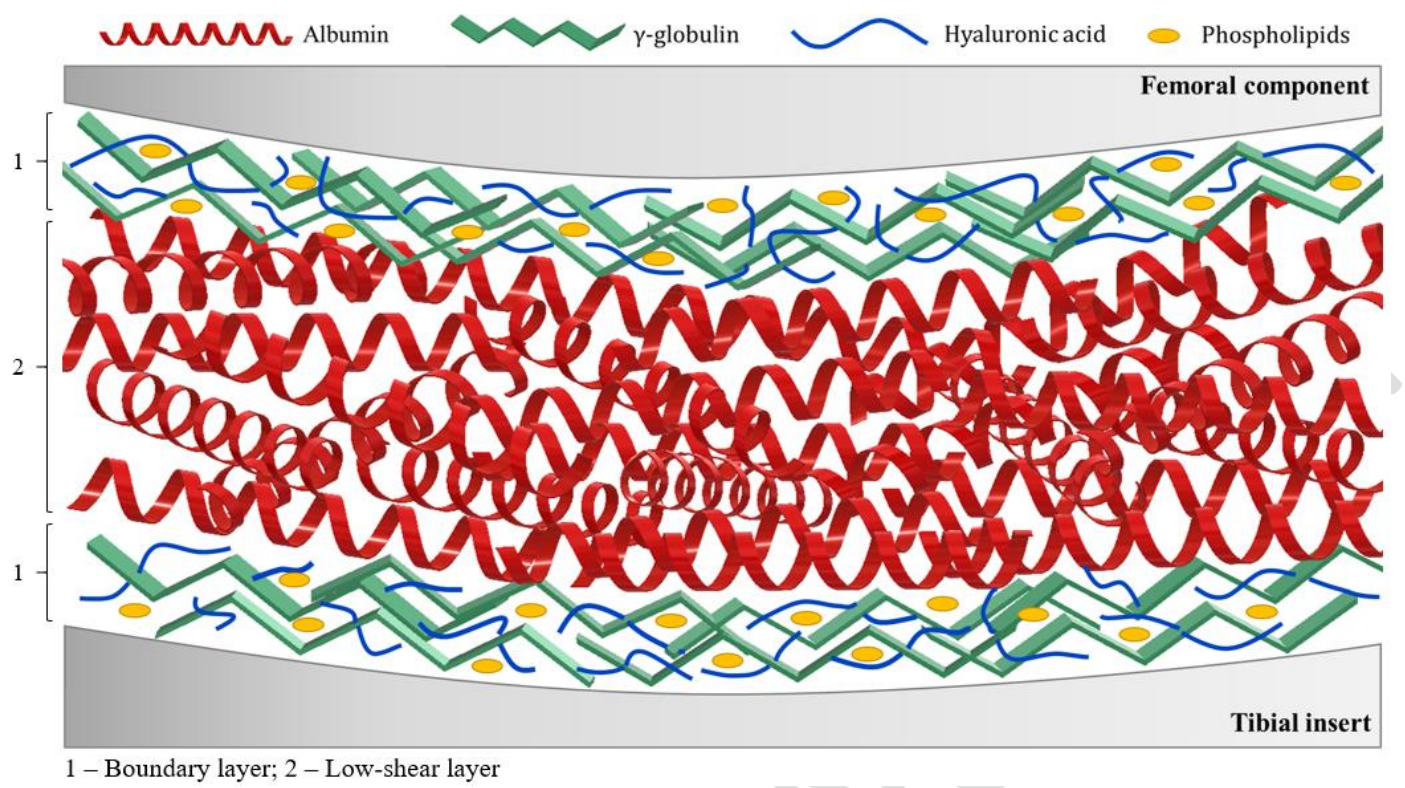

Fig. 9. Lubrication model of TKA.

\subsection{Data repeatability}

Synovial fluid lubrication is considered to be very complex and sensitive to measurement methodology. Ideally, all the experiments should be repeated multiple times in order to enable a detailed statistical evaluation. However, the present study employed 14 different lubricants, while the measurement repetition with all the fluids would unquestionably be very time and cost demanding. Regarding the fluid composition, this was designed to mimic diseased synovial fluid. Total protein concentration well corresponds to results published by Guenther et al. [76] (31 mg/ml versus $30 \mathrm{mg} / \mathrm{ml})$, who analyzed samples of osteoarthritic and periprosthetic synovial fluid of forty patients. Further, the applied concentration of albumin is similar to those recommended in literature [38]; however, concentration of $\gamma$-globulin, HA is lower while concentration of PLs is higher. The designed composition is based on ongoing analysis of synovial fluids samples extracted during revision surgeries. Nevertheless, lower HA concentration does not need to be necessarily considered to have a negative effect since it was shown that the concentration of HA has not a substantial impact on wear of XPE [42]. 
Moreover, the concentration of HA $(1.49 \mathrm{mg} / \mathrm{ml})$ is nearly identical to those applied by DesJardins et

478

479

480

481

482

483

484

485

486

487

488

489

490

491

492

493

494

495

496

497

498

499

500

501

502

al. [77], who performed rheological analysis of bovine serum mixed with $1.5 \mathrm{mg} / \mathrm{ml}$ of HA. The results indicated that the solution viscosity was not statistically different from those of synovial fluid taken during revision over a scope of shear rates corresponding to physiological conditions. Nevertheless, the lower viscosity of the applied lubricants (see Tab. 1) than reported in literature [38] is attributed mainly to lower concentration of HA and its lower molecular weight [78]. Referring to Fig. 3A, only a negligible variance of the results was observed for oil experiment which was repeated three times for all the investigated areas. Moreover, the authors recently published a number of studies dealing with lubrication of hip joints, establishing very strict laboratory protocols in order to eliminate external influences affecting the data. Nevertheless, four additional measurements were conducted with the use of simple protein (albumin, $\gamma$-globulin) solutions to demonstrate the repeatability.

As can be seen in Fig. 10A, there is a little variance for the lateral compartment while the difference of the end values is around $20 \%$. This difference is attributed to normalization process, which is undertaken as the first step during data evaluation. Each experiment starts at a different intensity level. This is due to three dominant factors such as (i) type of fluorescent marker used, (ii) ambient light conditions, and (iii) intensity of light source (listed from the most to the least influencing factors). For the comparison of the individual experiments, initial value of fluorescent intensity is thus set to a specific chosen value (1000 in the case of our study) while all the rest intensities are multiplied/divided by the normalization constant. Normalization is based on a single image taken right after start of the test. Due to the high frame rate, a couple of images may be chosen to represent a calibration image. The first image is not necessarily always the best. Thus, the data in Fig. 9A for the lateral condyle represent two extreme values of normalization constants. Despite that, the agreement of the data is very satisfactory. Focusing on the medial compartment, the compliance of the data is even better. Similar behavior may be seen for $\gamma$-globulin solution (Fig. 10B). The lateral compartment exhibits some differences; however, the change of the intensity is nearly negligible focusing on the scaled y-axis. For the medial compartment, the data are nearly identical, overlapping each other. 

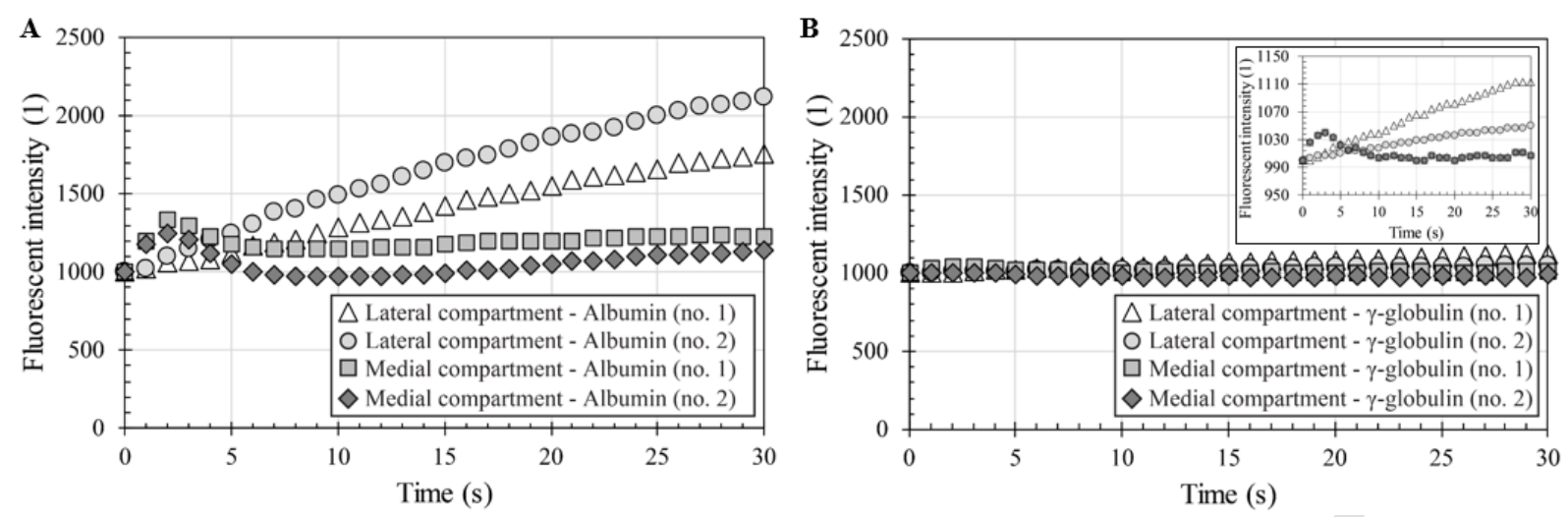

503

504

505

506

507

508

509

510

511

512

513

514

515

516

517

518

519

520

521

522

523

524

Fig. 10. (A) Illustration of data repeatability for albumin and $\gamma$-globulin solutions for lateral and (B) medial compartment. The detail in top right corner of Fig. 9B is the same graph with scaled y-axis.

Considerable proof of experimental repeatability also comes from Fig. 8. As it was described, the cumulative character of the diagram is based on repeating the tests lasting from 30 to $150 \mathrm{~s}$ while 30 s period was always recorded. The transition between the first and the second test for the lateral compartment was the only point where the data do not directly follow the previous curve. The explanation of higher emission right after start of the second test is that during the unrecorded period of the second test $(0-30 \mathrm{~s})$, the protein layer further increased. Further phases of the experiment revealed excellent continuity with the intensities at the beginnings of the individual experiments being almost identical with the intensities at the end of the previous test. This indicates that protein film at the lateral compartment increased for couple of tens of $\mathrm{s}$ after the motion starts with subsequent continuous thickness decrease. Considering the medial compartment, the film dropped at the beginning which was followed by a slight increase during the first thirty s (Fig. 10B). This behavior corresponds to observation displayed in Fig. 7B (grey rhomb data). With increasing time, the film continuously decreased while perfect continuity of each following test may be observed. Based on above, it is tempting to conclude that longer uninterrupted walking leads to deterioration of lubrication conditions within TKA, negatively affecting the service life of the implant. If proved by other experiments, an interrupted walking alternated with unloading phase enabling film recovery could be recommended in order to prolong the longevity of TKA. The issue of decreasing film thickness under interrupted loading can be considered as the main outcome of this experiment. The evidence of data repeatability is in very good agreement of 
the end and initial values of each subsequent measurement steps. As described, every recorded phase was preceded by time corresponding to the length of the previous test for what the experiment ran without recording. For example, during the third test, time range from $60 \mathrm{~s}$ to $90 \mathrm{~s}$ was recorded while the whole test lasted for 90 seconds. The fact that the results at the beginning of recorded phase of experiment no. 3 directly follows end values of experiment no. 2 indicate high level of measurement repeatability.

\subsection{Limitations}

The author admit couple of limitations of the performed study. At first, the used transparent PMMA insert may behave differently compare to conventional UHMWPE to some extent. This a difference is related to contact mechanics. In general, TKA is exposed to higher contact stress than THA due to variable geometry of the compartments and generally smaller contact area. Although the contact pressure achieved in this study corresponds to metal-UHMWPE pairs, the resulting contact area is smaller for metal-PMMA contact. This is due higher elastic modulus of PMMA driving the elastic deformation of the material. However, even in the case of PMMA, contact area in specific locations ranges from 2 to $5 \mathrm{~mm}$, which is sufficient for the assessment of the formation of lubricant film. The differences of PMMA and UHMWPE are further discussed in the recent paper [47] and in Part II [34]. Further, IE rotation was fixed in the present study while lubricant film may be partially affected by this additional motion. However, based on the current observation, it is concluded that the formed film was stable even at the phases of the cycle when sliding occurred. Thus, it is expected that consideration of IE rotation might have some quantitative impact on the film thickness but not on qualitative character of film formation. Finally, some uncertainty can also be related to proteins and their interactions with biomaterial, or among themselves in vivo. In particular, the risk associated with conformational changes of albumin, potentially leading to increased wear reported in literature, needs to be considered [39]. Neither the contact pressure nor the expected temperature increase in the contact are high enough to cause change of the proteins structure. These effects are further studied in Part II [34]. Since model fluid with controlled composition was used, conformational changes due to interaction with other constituents (e.g. bilirubin) could not occur as well. Nevertheless, focusing on the real-environment conditions in 
human body, these processes definitely play a role. Further, the differences of synovial fluid composition [43] together with the action of antimicrobial agents, polypeptides [40] were not considered. However, these limitations are common to many in vitro studies. Some level on uncertainty may also arise from a limited amount of the applied lubricant (around $10 \mathrm{ml}$ used for full flooding of the tibial insert) as it was reported that smaller volume of the fluid leads to higher degree of degradation [79]. Nevertheless, this is rather closely related to long-term wear tests as most of the experiments performed in the present study lasted couple minutes including test preparation.

\section{Conclusion}

The present contribution concentrated on the assessment of lubricant film formation within TKA. The tests were performed with the use of knee test rig while the metal femoral component was in contact with the transparent polymer insert. The contact was observed using the fluorescent microscopy method. Transient dynamic conditions were applied. Initially, the contact was lubricated by mineral oil enabling to compare the experimental investigation with the developed numerical model which is presented in Part II [34]. Further experiments were realized using various lubricants, revealing the impact of specific synovial fluid constituents on evolution of film thickness during the gait cycle. The main conclusions are:

- Unique approach built on the direct optical monitoring of film formation in TKA was presented. Initial investigation considering mineral oil as the test lubricant revealed very good agreement of both experimental and numerical approaches [34].

- Based on the assessment of the behavior of albumin, $\gamma$-globulin, and HA in model synovial fluids of different degrees of complexity, a lubrication model for TKA was proposed.

- It is suggested that $\gamma$-globulin is strongly adsorbed to the substrate, creating a boundary lubricating layer which is reinforced by HA and PL molecules. Further enhancement of lubricant layer is due to layering of low-shear albumin layer.

- The medial condyle shows worse lubrication conditions which may potentially lead to shortening of service life of the TKA. 
- Based on the observation of continuous decrease in film thickness, interrupted walking with rest periods may beneficially influence the film recovery. Resting periods may therefore be clinically important to improve implant longevity.

\section{Acknowledgements}

This work was supported by the Ministry of Education, Youth and Sports of the Czech Republic (LTAUSA17150) and RVO 61989592. M. Marian, B. Rothammer, S. Tremmel and S. Wartzack greatly acknowledge the continuous support of Friedrich-Alexander-Universität Erlangen-Nürnberg (FAU), Germany. J. Gallo was supported by IGA_LF_2020_015. The authors thank to T. Sýkora who was involved in experimental study.

\section{Author's contributions}

D. Nečas, M. Vrbka and M. Marian conceived the idea. D. Nečas designed, performed and analyzed the experiments. A. Galandáková prepared the model fluids. D. Nečas, M. Marian, J. Gallo and M.A. Wimmer wrote the original draft of the manuscript. M. Hartl and I. Křupka supervised the study. All authors provided suggestions for the final discussions, reviewed, edited and read the mansucript as well as approved the final version.

\section{References}

[1] Cook R, Davidson P, Martin R. More than $80 \%$ of total knee replacements can last for 25 years. Bmj. 2019;367:15680.

[2] Ferket BS, Feldman Z, Zhou J, Oei EH, Bierma-Zeinstra SMA, Mazumdar M. Impact of total knee replacement practice: cost effectiveness analysis of data from the Osteoarthritis Initiative. Bmj. 2017;356:1331-1340.

[3] Carr AJ, Robertsson O, Graves S, Price AJ, Arden NK, Judge A, et al. Knee replacement. The Lancet 2012;379:1331-1340.

[4] Price AJ, Alvand A, Troelsen A, Katz JN, Hooper G, Gray A, et al. Knee replacement. The Lancet 2018;392:1672-1682. 
[5] Pietrzak J, Common H, Migaud H, Pasquier G, Girard J, Putman S. Have the frequency of and reasons for revision total knee arthroplasty changed since 2000? Comparison of two cohorts from the same hospital: 255 cases (2013-2016) and 68 cases (1991-1998). Orthopaedics \& Traumatology: Surgery \& Research 2019;105:639-645.

[6] Gallo J, Goodman SB, Konttinen YT, Wimmer MA, Holinka M. Osteolysis around total knee arthroplasty: A review of pathogenetic mechanisms. Acta Biomaterialia 2013;9:8046-8058.

[7] Australian Orthopaedic Association National Joint Replacement Registry (AOANJRR). Hip, Knee \& Shoulder Arthroplasty: 2020 Annual Report, Adelaide; AOA, 2020: 1-474.

[8] American Joint Replacement Registry (AJRR): 2020 Annual Report. Rosemont, IL: American Academy of Orthopaedic Surgeons (AAOS), 2020.

[9] Shi J, Zhu W, Liang S, Li H, Li S. Cross-Linked Versus Conventional Polyethylene for LongTerm Clinical Outcomes After Total Hip Arthroplasty: A Systematic Review and MetaAnalysis. Journal Of Investigative Surgery 2019:1-11.

[10] Evans JT, Walker RW, Evans JP, Blom AW, Sayers A, Whitehouse MR. How long does a knee replacement last? A systematic review and meta-analysis of case series and national registry reports with more than 15 years of follow-up. The Lancet 2019;393:655-663.

[11] McKellop HA. The lexicon of polyethylene wear in artificial joints. Biomaterials 2007;28:50495057.

[12] Knowlton CB, Bhutani P, Wimmer MA. Relationship of surface damage appearance and volumetric wear in retrieved TKR polyethylene liners. Journal Of Biomedical Materials Research Part B: Applied Biomaterials 2017;105:2053-2059.

[13] Spece H, Schachtner JT, MacDonald DW, Klein GR, Mont MA, Lee G-C, et al. Reasons for Revision, Oxidation, and Damage Mechanisms of Retrieved Vitamin E-Stabilized Highly Crosslinked Polyethylene in Total Knee Arthroplasty. The Journal Of Arthroplasty 2019;34:3088-3093.

[14] Fulin P, Slouf M, Krejcikova S, Nevoralova M, Sticha R, Pokorny D. Ccomparison of explanted uhmwpe hip replacement components of various manufacturers after 10 years in vivo. Acta Chir Orthop Traumatol Cech. 2019;86:390-396. 
[15] Chakrabarty G, Vashishtha M, Leeder D. Polyethylene in knee arthroplasty: A review. Journal Of Clinical Orthopaedics And Trauma 2015;6:108-112.

[16] MacDonald DW, Higgs GB, Chen AF, Malkani AL, Mont MA, Kurtz SM. Oxidation, Damage Mechanisms, and Reasons for Revision of Sequentially Annealed Highly Crosslinked Polyethylene in Total Knee Arthroplasty. The Journal Of Arthroplasty 2018;33:1235-1241.

[17] Pourzal R, Knowlton CB, Hall DJ, Laurent MP, Urban RM, Wimmer MA. How Does Wear Rate Compare in Well-functioning Total Hip and Knee Replacements? A Postmortem Polyethylene Liner Study. Clinical Orthopaedics And Related Research® 2016;474:1867-1875.

[18] Ngai V, Kunze J, Cip J, Laurent MP, Jacobs JJ, Wimmer MA. Backside wear of tibial polyethylene components is affected by gait pattern: A knee simulator study using rare earth tracer technology. Journal Of Orthopaedic Research. 2020.

[19] Chen Z, Zhang J, Gao Y, Chen S, Zhang X, Jin Z. Effects of interference assembly of a tibial insert on the tibiofemoral contact mechanics in total knee replacement. Proceedings Of The Institution Of Mechanical Engineers, Part H: Journal Of Engineering In Medicine 2019;233:948-953.

[20] Mihalko WM, Haider H, Kurtz S, Marcolongo M, Urish K. New materials for hip and knee joint replacement: What's hip and what's in kneed? Journal Of Orthopaedic Research. 2020.

[21] Inacio MCS, Paxton EW, Graves SE, Namba RS, Nemes S. Projected increase in total knee arthroplasty in the United States - an alternative projection model. Osteoarthritis And Cartilage 2017;25:1797-1803.

[22] Brown TS, Van Citters DW, Berry DJ, Abdel MP. The use of highly crosslinked polyethylene in total knee arthroplasty. The Bone \& Joint Journal 2017;99-B:996-1002.

[23] Orita K, Minoda Y, Sugama R, Ohta Y, Ueyama H, Takemura S, et al. Vitamin E-infused highly cross-linked polyethylene did not reduce the number of in vivo wear particles in total knee arthroplasty. The Bone \& Joint Journal 2020;102-B:1527-1534.

[24] Liu T, Esposito C, Elpers M, Wright T. Surface Damage Is Not Reduced With Highly Crosslinked Polyethylene Tibial Inserts at Short-term. Clinical Orthopaedics And Related Research ${ }^{\circledR} 2016 ; 474: 107-116$. 
[25] Illgen RL, Forsythe TM, Pike JW, Laurent MP, Blanchard CR. Highly Crosslinked vs Conventional Polyethylene Particles-An In Vitro Comparison of Biologic Activities. The Journal Of Arthroplasty 2008;23:721-731.

[26] Huang C-H, Lu Y-C, Chang T-K, Hsiao I-L, Su Y-C, Yeh S-T, et al. In vivo biological response to highly cross-linked and vitamin e-doped polyethylene-a particle-Induced osteolysis animal study. Journal Of Biomedical Materials Research Part B: Applied Biomaterials 2016;104:561567.

[27] Chen W, Bichara DA, Suhardi J, Sheng P, Muratoglu OK. Effects of vitamin E-diffused highly cross-linked UHMWPE particles on inflammation, apoptosis and immune response against S. aureus. Biomaterials 2017;143:46-56.

[28] Baxter RM, MacDonald DW, Kurtz SM, Steinbeck MJ. Characteristics of highly cross-linked polyethylene wear debris in vivo. Journal Of Biomedical Materials Research Part B: Applied Biomaterials 2013:

[29] Minoda Y, Kobayashi A, Sakawa A, Aihara M, Tada K, Sugama R, et al. Wear particle analysis of highly crosslinked polyethylene isolated from a failed total hip arthroplasty. Journal Of Biomedical Materials Research Part B: Applied Biomaterials 2008;86B:501-505.

[30] ISO 14243-1. Implants for surgery - Wear of total knee-joint prostheses - Part 1: Loading and displacement parameters for wear-testing machines with load control and corresponding environmental conditions for test. 2009.

[31] ISO 14243-3 Implants for surgery - Wear of total knee-joint prostheses - Part 3: Loading and displacement parameters for wear-testing machines with displacement control and corresponding environmental conditions for test. 2014.

[32] Wang X-H, Zhang W, Song D-Y, Li H, Dong X, Zhang M, et al. The impact of variations in input directions according to ISO 14243 on wearing of knee prostheses. Plos One 2018;13:e0206496.

[33] Serro AP, Degiampietro K, Colaço R, Saramago B. Adsorption of albumin and sodium hyaluronate on UHMWPE: A QCM-D and AFM study. Colloids And Surfaces B: Biointerfaces 2010;78:1-7. 
[34] Marian M, Orgeldinger C, Rothammer B, Nečas D, Vrbka M, Křupka I, Hartl M, Wimmer MA, Tremmel S, Wartzack S. Towards the Understanding of Lubrication Mechanisms in Total Knee Replacements - Part II: Numerical Modeling. /Unpublished results/.

[35] Ohtsuki N, Murakami T, Moriyama S, Higaki H. Influence of Geometry of Conjunction on Elastohydrodynamic Film Formation in Knee Prostheses with Compliant Layer. Elastohydrodynamics - '96 Fundamentals and Applications in Lubrication and Traction, Proceedings of the 23rd Leeds-Lyon Symposium on Tribology held in the Institute of Tribology, Department of Mechanical Engineering, Elsevier; 1997, pp. 349-359.

[36] Scholes SC, Unsworth A. The Effects of Proteins on the Friction and Lubrication of Artificial Joints. Proceedings Of The Institution Of Mechanical Engineers, Part H: Journal Of Engineering In Medicine 2006;220:687-693.

[37] Scholes SC, Unsworth A, Jones E. Polyurethane unicondylar knee prostheses: simulator wear tests and lubrication studies. Physics In Medicine And Biology 2007;52:197-212.

[38] Bortel E, Charbonnier B, Heuberger R. Development of a Synthetic Synovial Fluid for Tribological Testing. Lubricants 2015;3:664-686.

[39] Fullam S, He J, Scholl CS, Schmid TM, Wimmer MA. Competitive Binding of Bilirubin and Fatty Acid on Serum Albumin Affects Wear of UHMWPE. Lubricants 2020;8.

[40] Brandt J-M, Charron K, Zhao L, MacDonald SJ, Medley JB. Calf serum constituent fractions influence polyethylene wear and microbial growth in knee simulator testing. Proceedings Of The Institution Of Mechanical Engineers, Part H: Journal Of Engineering In Medicine 2012;226:427-440.

[41] Brandt J-M, Mahmoud KK, Koval SF, MacDonald SJ, Medley JB. Antimicrobial agents and low-molecular weight polypeptides affect polyethylene wear in knee simulator testing. Tribology International 2013;65:97-104.

[42] Guenther LE, Turgeon TR, Bohm ER, Brandt J-M. The biochemical characteristics of wear testing lubricants affect polyethylene wear in orthopaedic pin-on-disc testing. Proceedings Of The Institution Of Mechanical Engineers, Part H: Journal Of Engineering In Medicine 2015;229:77-90. 
[43] Galandáková A, Ulrichová J, Langová K, Hanáková A, Vrbka M, Hartl M, et al. Characteristics of synovial fluid required for optimization of lubrication fluid for biotribological experiments. Journal Of Biomedical Materials Research Part B: Applied Biomaterials 2017;105:1422-1431.

723

724

725

[44] Flannery M, McGloughlin T, Jones E, Birkinshaw C. Analysis of wear and friction of total knee replacements. Wear 2008;265:999-1008.

[45] Flannery M, Jones E, Birkinshaw C. Analysis of wear and friction of total knee replacements part II: Friction and lubrication as a function of wear. Wear 2008;265:1009-1016.

[46] Nečas D, Sadecká K, Vrbka M, Gallo J, Galandáková A, Křupka I, et al. Observation of lubrication mechanisms in knee replacement: A pilot study. Biotribology 2019;17:1-7.

[47] Nečas D, Sadecká K, Vrbka M, Galandáková A, Wimmer MA, Gallo J, Hartl M. The Effect of Albumin and $\gamma$-globulin on Synovial Fluid Lubrication: Implication for Knee Joint Replacements. Journal Of The Mechanical Behavior Of Biomedical Materials 2021;113: 104117.

[48] Nečas D, Vrbka M, Galandáková A, Křupka I, Hartl M. On the observation of lubrication mechanisms within hip joint replacements. Part I: Hard-on-soft bearing pairs. Journal Of The Mechanical Behavior Of Biomedical Materials 2019;89:237-248.

[49] Nečas D, Vrbka M, Gallo J, Křupka I, Hartl M. On the observation of lubrication mechanisms within hip joint replacements. Part II: Hard-on-hard bearing pairs. Journal Of The Mechanical Behavior Of Biomedical Materials 2019;89:249-259.

[50] Albahrani S, Philippon D, Vergne P, Bluet J. A review of in situ methodologies for studying elastohydrodynamic lubrication. Proceedings Of The Institution Of Mechanical Engineers, Part J: Journal Of Engineering Tribology 2015;230:86-110.

[51] Myant C, Reddyhoff T, Spikes HA. Laser-induced fluorescence for film thickness mapping in pure sliding lubricated, compliant, contacts. Tribology International 2010;43:1960-1969.

[52] Fowell MT, Myant C, Spikes HA, Kadiric A. A study of lubricant film thickness in compliant contacts of elastomeric seal materials using a laser induced fluorescence technique. Tribology International 2014;80:76-89. 
[53] Nečas D, Jaroš T, Dockal K, Šperka P, Vrbka M, Krupka I, et al. The Effect of Kinematic Conditions on Film Thickness in Compliant Lubricated Contact. Journal Of Tribology 2018;140:051501-.

[54] Zhang L, Xu C, Li B. Simple and sensitive detection method for chromium(VI) in water using glutathione-capped CdTe quantum dots as fluorescent probes. Microchimica Acta 2009;166:61-68.

[55] Sugimura J, Hashimoto M, Yamamoto Y. Study of elastohydrodynamic contacts with fluorescence microscope. Proceedings Of The 26Th Leeds-Lyon Symposium On Tribology, Elsevier, 2000, p. 609-317.

[56] Azushima A. In situ 3D measurement of lubrication behavior at interface between tool and workpiece by direct fluorescence observation technique. Wear 2006;260:243-248.

[57] Mischler S, Barril S, Landolt D. Fretting corrosion behaviour of Ti-6Al-4V/PMMA contact in simulated body fluid. Tribology - Materials, Surfaces \& Interfaces 2013;3:16-23.

[58] Ford RAJ, Foord CA. Laser-based fluorescence techniques for measuring thin liquid films. Wear 1978;51:289-297.

[59] Pascau A, Guardia B, Puertolas JA, Gómez-Barrena E. Knee model of hydrodynamic lubrication during the gait cycle and the influence of prosthetic joint conformity. Journal Of Orthopaedic Science 2009;14:68-75.

[60] Mongkolwongrojn M, Wongseedakaew K, Kennedy FE. Transient elastohydrodynamic lubrication in artificial knee joint with non-Newtonian fluids. Tribology International 2010;43:1017-1026.

[61] Nečas D, Vrbka M, Rebenda D, Gallo J, Galandáková A, Wolfová L, et al. In situ observation of lubricant film formation in THR considering real conformity: The effect of model synovial fluid composition. Tribology International 2018;117:206-216.

[62] Hidrovo $\mathrm{CH}$, Hart DP. Emission reabsorption laser induced fluorescence (ERLIF) film thickness measurement. Measurement Science And Technology 2001;12:467-477.

[63] Yan Y, Yang H, Su Y, Qiao L. Albumin adsorption on CoCrMo alloy surfaces. Scientific Reports 2016;5. 
[64] Malmsten M. Formation of Adsorbed Protein Layers. Journal Of Colloid And Interface Science 1998;207:186-199.

[65] Ko JS, Cho K, Han SW, Sung HK, Baek SW, Koh W-G, et al. Hydrophilic surface modification of poly(methyl methacrylate)-based ocular prostheses using poly(ethylene glycol) grafting. Colloids And Surfaces B: Biointerfaces 2017;158:287-294.

[66] Nakashima K, Sawae Y, Murakami T. Study on Wear Reduction Mechanisms of Artificial Cartilage by Synergistic Protein Boundary Film Formation. Jsme International Journal Series C 2005;48:555-561.

[67] Nakashima K, Sawae Y, Murakami T. Effect of conformational changes and differences of proteins on frictional properties of poly(vinyl alcohol) hydrogel. Tribology International 2007;40:1423-1427.

[68] Nakashima K, Sawae Y, Murakami T. Influence of protein conformation on frictional properties of poly (vinyl alcohol) hydrogel for artificial cartilage. Tribology Letters 2007;26:145-151.

[69] Duong C-T, Lee J-H, Cho Y, Nam J-S, Kim H-N, Lee S-S, et al. Effect of protein concentrations of bovine serum albumin and $\gamma$-globulin on the frictional response of a cobalt-chromium femoral head. Journal Of Materials Science: Materials In Medicine 2012;23:1323-1330.

[70] Yarimitsu S, Nakashima K, Sawae Y, Murakami T, Influences of lubricant composition on forming boundary film composed of synovia constituents, Tribology International. 42 (2009) $1615-1623$.

[71] Hirschmann MT, Becker R. The Unhappy Total Knee Replacement. Cham: Springer International Publishing; 2015.

[72] Rad EM, Laurent MP, Knowlton CB, Lundberg HJ, Pourzal RR, Wimmer MA. Linear Penetration as a Surrogate Measure for Volumetric Wear in TKR Tibial Inserts. Beyond the Implant: Retrieval Analysis Methods for Implant Surveillance, 100 Barr Harbor Drive, Po Box C700, West Conshohocken, Pa 19428-2959: ASTM International; 2018, pp. 75-92.

[73] O'Brien ST, Luo Y, Brandt J-M. In-vitro and in-silico investigations on the influence of contact pressure on cross-linked polyethylene wear in total knee replacements. Wear 2015;332333:687-693. 
[74] Meng F, Jaeger S, Sonntag R, Schroeder S, Smith-Romanski S, Kretzer JP. How prosthetic design influences knee kinematics: a narrative review of tibiofemoral kinematics of healthy and joint-replaced knees. Expert Review Of Medical Devices 2019;16:119-133.

[75] Lahuec C, Almouahed S, Arzel M, Gupta D, Hamitouche C, Jézéquel M, et al. A Self-Powered Telemetry System to Estimate the Postoperative Instability of a Knee Implant. Ieee Transactions On Biomedical Engineering 2011;58:822-825.

[76] Guenther LE, Pyle BW, Turgeon TR, Bohm ER, Wyss UP, Schmidt TA, et al. Biochemical analyses of human osteoarthritic and periprosthetic synovial fluid. Proceedings Of The Institution Of Mechanical Engineers, Part H: Journal Of Engineering In Medicine 2014;228:127-139.

[77] DesJardins J, Aurora A, Tanner SL, Pace TB, Acampora KB, LaBerge M. Increased Total Knee Arthroplasty Ultra-High Molecular Weight Polyethylene Wear Using a Clinically Relevant Hyaluronic Acid Simulator Lubricant. Proceedings Of The Institution Of Mechanical Engineers, Part H: Journal Of Engineering In Medicine 2006;220:609-623.

[78] Rebenda D, Vrbka M, Čípek P, Toropitsyn E, Nečas D, Pravda M, et al. On the Dependence of Rheology of Hyaluronic Acid Solutions and Frictional Behavior of Articular Cartilage. Materials 2020;13.

[79] Reinders J, Sonntag R, Kretzer JP. Synovial fluid replication in knee wear testing: An investigation of the fluid volume. Journal Of Orthopaedic Research 2015;33:92-97. 